Supporting Information for:

\title{
The Total Synthesis of (-)-Lemonomycin
}

\author{
Eric R. Ashley, Ernest G. Cruz, and Brian M. Stoltz*
}

\begin{abstract}
The Arnold and Mabel Beckman Laboratories of Chemical Synthesis, Division of Chemistry and Chemical Engineering, California Institute of Technology, Pasadena, California 91125, USA
\end{abstract}

Material and Methods. Unless otherwise stated, reactions were performed at ambient temperature (typically $20{ }^{\circ} \mathrm{C}$ ) in flame-dried glassware under a nitrogen or argon atmosphere using dry, deoxygenated solvents. Solvents were dried by passage through an activated alumina column under argon. Acrolein was distilled under nitrogen immediately prior to use. All other commercially obtained reagents were used as received. Reaction temperatures were controlled by an IKAmag temperature modulator. Thin-layer chromatography (TLC) was performed using E. Merck silica gel 60 F254 precoated plates $(0.25 \mathrm{~mm})$ and visualized by UV, anisaldehyde, permanganate, or CAM staining. ICN Silica gel (particle size $0.032-0.063 \mathrm{~mm}$ ) was used for flash chromatography. Preparatory reversed-phase HPLC was performed on a Waters HPLC with a Waters Delta-Pak $25 \times 100 \mathrm{~mm}, 15 \square \mathrm{m} \mathrm{C}_{18}$ column equipped with a guard, utilizing a flow rate of $10 \mathrm{~mL} / \mathrm{min}$ and a ramp of $1 \% \mathrm{~B} / \mathrm{min}$ (A eluent $=95: 5: 0.05$ water:acetonitrile:trifluoroacetic acid, $B$ eluent $=5: 95: 0.01$ water:acetonitrile:trifluoroacetic acid) with visualization at $270 \mathrm{~nm}$. Analytical chiral HPLC was performed with an Agilent 1100 Series HPLC utilizing a chiralcel AD column $(4.6 \mathrm{~mm} \times 25 \mathrm{~cm})$ obtained from Daicel Chemical Industries, Ltd with visualization at $254 \mathrm{~nm}$. Optical rotations were measured with a Jasco P-1010 polarimeter. ${ }^{1} \mathrm{H}$ and ${ }^{13} \mathrm{C}$ NMR spectra were recorded on either a Varian Mercury 300 (at $300 \mathrm{MHz}$ and $75 \mathrm{MHz}$ respectively), Varian Mercury 500 (at $500 \mathrm{MHz}$ and $125 \mathrm{MHz}$ respectively), or on a Varian Mercury 600 (600 $\mathrm{MHz}$ for proton only) spectrometer and are reported relative to $\mathrm{Me}_{4} \mathrm{Si}(\square 0.0)$. Data for ${ }^{1} \mathrm{H}$ NMR spectra are reported as follows: chemical shift $(\square \mathrm{ppm})$, multiplicity, coupling constant $(\mathrm{Hz})$ and integration. Data for ${ }^{13} \mathrm{C}$ NMR spectra are reported in terms of chemical shift. IR spectra were recorded on a Perkin Elmer Paragon 1000 spectrometer and are reported in frequency of absorption $\left(\mathrm{cm}^{-1}\right)$. UV spectra were measured on a Beckman-Coulter DU 7400 spectrophotometer. High resolution mass spectra were obtained from the Caltech Mass Spectral Facility. Crystallographic data have been deposited at the CCDC, 12 Union Road, Cambridge CB2 1EZ, UK and copies can be obtained on request, free of charge, by quoting the publication citation and the deposition number (see individual structures for deposition number).

\section{Additional References.}

Natural product isolates containing the aminopyranose of lemonomycin (footnote 4); the saccharosacrins (a-b) and the glycothiohexides (c-e):

(a) Hegde, V. R.; Patel, M. G.; Das, P. R.; Pramanik, B.; Puar, M. S. J.Antibiot. 1997, 50, 126134. (b) Horan, A. C.; Shearer, M. C.; Hegde, V.; Beyazova, M. L.; Brodsky, B. C.; King, A,; Berrie, R,; Cardaci, K, Nimeck, M.. J.Antibiot. 1997, 50, 119-125. (c) Sasaki, T.; Otani, T.; Matsumoto, H.; Unemi, N.; Hamada, M.; Takeuchi, T.; Hori, M. J.Antibiot. 1998, 51, 715-721. (d) Northcote, P. T.; Siegel, M.; Borders, D. B.; Lee, M. D. J.Antibiot. 1994, 47, 901-908. (e) Constatntine, K. L.; Mueller, L.; Huang, S.; Abid, S.; Lam, K. S.; Li, W.; Leet, J. E. J. Am. Chem. Soc. 2002, 124, 7284-7285. 


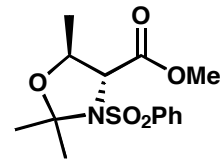

$(+)-S 11$

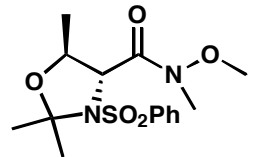

$(+)-S 12$

Amide (+)-SI2. A suspension of $\mathrm{N}, \mathrm{O}$-dimethylhydroxylamine hydrochloride $(1.54 \mathrm{~g}, 15.8$ $\mathrm{mmol})$ in tetrahydrofuran $(100 \mathrm{~mL})$ was cooled to $-78^{\circ} \mathrm{C}$ and $i$-propylmagnesium chloride $(16.0$ $\mathrm{mL}, 32.0 \mathrm{mmol})$ was added. After stirring for $5 \mathrm{~min}$, a solution of ester $(+)-\mathbf{S I 1}^{1}(2.26 \mathrm{~g}, 7.21$ $\mathrm{mmol})$ in tetrahydrofuran $(20 \mathrm{~mL})$ was added. The mixture was stirred at $-78{ }^{\circ} \mathrm{C}$ for $30 \mathrm{~min}$ then at $-40{ }^{\circ} \mathrm{C} 12 \mathrm{~h}$. The reaction was quenched with saturated aqueous ammonium chloride (100 $\mathrm{mL})$, extracted with ethyl acetate $(4 \times 100 \mathrm{~mL})$, washed with brine, and dried over sodium sulfate. Solvent was evaporated and the residue was purified by flash chromatography (4:1 hexanes:ethyl acetate eluent) to provide amide $(+)-S I 2(2.24 \mathrm{~g}, 91 \%$ yield $)$ as a white solid: $\mathrm{R}_{\mathrm{F}}$ 0.27 (50:50 hexanes:ethyl acetate eluent); ${ }^{1} \mathrm{H}$ NMR $\left(300 \mathrm{MHz}, \mathrm{CDCl}_{3}\right) \square$ 8.05-8.01 (comp m, 2H), 7.63-7.51 (m, 3H), $4.66(\mathrm{~d}, J=7.0 \mathrm{~Hz}, 1 \mathrm{H}), 4.26(\mathrm{~m}, 1 \mathrm{H}), 3.80(\mathrm{~s}, 3 \mathrm{H}), 3.23(\mathrm{~s}, 3 \mathrm{H}), 1.54$ $(\mathrm{s}, 3 \mathrm{H}), 1.49(\mathrm{~s}, 3 \mathrm{H}), 1.35(\mathrm{~d}, J=6.0 \mathrm{~Hz}, 3 \mathrm{H}) ;{ }^{13} \mathrm{C}$ NMR $\left(75 \mathrm{MHz}, \mathrm{CDCl}_{3}\right) \square 132.8,128.8$, 128.0, 97.3, 74.8, 64.2, 61.4, 27.4, 18.8; IR (NaCl/film) 2982, 1677, 1447, $1344 \mathrm{~cm}^{-1}$; HRMS (FAB) $m / z$ calc'd for $\left[\mathrm{C}_{15} \mathrm{H}_{22} \mathrm{~N}_{2} \mathrm{O}_{5} \mathrm{~S}+\mathrm{H}\right]^{+}: 343.1328$, found 343.1312 ; [ $]_{\mathrm{D}}{ }^{25}+71.9^{\circ}(\mathrm{c}=1.00$, $\left.\mathrm{CHCl}_{3}\right)$.

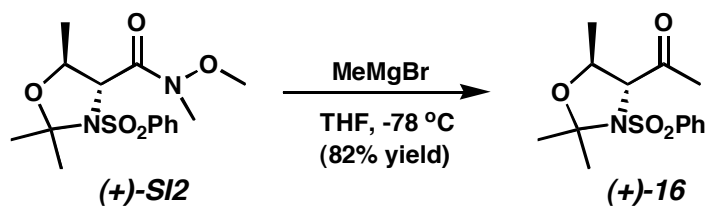

Ketone (+)-16. Amide (+)-SI2 $(1.64 \mathrm{~g}, 4.79 \mathrm{mmol})$ was dissolved in tetrahydrofuran $(20 \mathrm{~mL})$ and cooled to $-78{ }^{\circ} \mathrm{C}$. To the solution was added methylmagnesium bromide $(1.8 \mathrm{~mL}, 5.4$ mmol). After $45 \mathrm{~min}$, additional methylmagnesium bromide $(1.8 \mathrm{~mL}, 5.4 \mathrm{mmol})$ was added. The solution was allowed to warm to rt. The reaction was quenched with saturated aqueous ammonium chloride $(50 \mathrm{~mL})$ and extracted with ethyl acetate $(3 \times 50 \mathrm{~mL})$. The combined organics were dried over sodium sulfate and evaporated. The residue was purified by flash chromatography (4:1 to 1:1 hexanes:ethyl acetate eluent) to yield ketone $(+)-16(1.30 \mathrm{~g}, 82 \%$ yield) as a white solid : $\mathrm{R}_{\mathrm{F}} 0.38$ (70:30 hexanes:ethyl acetate eluent); ${ }^{1} \mathrm{H}$ NMR (300 MHz, $\left.\mathrm{CDCl}_{3}\right) \square 7.86(\mathrm{~m}, 2 \mathrm{H}), 7.64-7.51(\mathrm{comp} \mathrm{m}, 3 \mathrm{H}), 4.22(\mathrm{~m}, 1 \mathrm{H}), 3.70(\mathrm{~d}, J=8.0 \mathrm{~Hz}, 1 \mathrm{H}), 2.42(\mathrm{~s}$, $3 \mathrm{H}), 1.69(\mathrm{~s}, 3 \mathrm{H}), 1.49(\mathrm{~s}, 3 \mathrm{H}), 1.26(\mathrm{~d}, J=6.0 \mathrm{~Hz}, 3 \mathrm{H}) ;{ }^{13} \mathrm{C} \mathrm{NMR}\left(75 \mathrm{MHz}, \mathrm{CDCl}_{3}\right) \square 205.5$, 139.7, 133.1, 129.2, 127.8, 98.2, 74.6, 72.8, 28.8, 25.8, 25.0, 17.9; IR (NaCl/film) 2987, 1716, 1344, $1157 \mathrm{~cm}^{-1}$; HRMS (FAB) $\mathrm{m} / z$ calc'd for $\left[\mathrm{C}_{14} \mathrm{H}_{19} \mathrm{NO}_{4} \mathrm{~S}+\mathrm{H}\right]^{+}$: 298.1113, found 298.1101; $[\square]_{\mathrm{D}}^{26}+148.0^{\circ}\left(\mathrm{c}=1.00, \mathrm{CHCl}_{3}\right)$. 


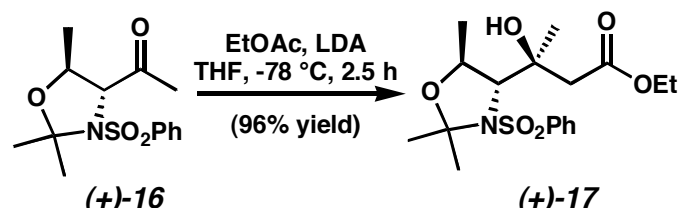

Aldol adduct (+)-17. A solution of diisopropylamine $(11.3 \mathrm{~mL}, 80.9 \mathrm{mmol})$ in tetrahydrofuran ( $77 \mathrm{~mL}$ ) was cooled to $0^{\circ} \mathrm{C}$ and $n$-butyllithium $(30 \mathrm{~mL}, 76 \mathrm{mmol})$ was added. After $20 \mathrm{~min}$, the solution was cooled to $-78{ }^{\circ} \mathrm{C}$, and a solution of ethyl acetate $(7.5 \mathrm{~mL}, 77 \mathrm{mmol})$ in tetrahydrofuran $(154 \mathrm{~mL})$ was added dropwise over $5 \mathrm{~min}$. After $1 \mathrm{~h}$, a solution of ketone $(+)-16$ $(4.83 \mathrm{~g}, 16.2 \mathrm{mmol})$ in tetrahydrofuran $(81 \mathrm{~mL})$ at $-78{ }^{\circ} \mathrm{C}$ was added via cannula. The reaction was quenched after $2.5 \mathrm{~h}$ with saturated aqueous ammonium chloride $(100 \mathrm{~mL})$. The mixture was allowed to warm to $\mathrm{rt}$, and partitioned between water $(100 \mathrm{~mL})$ and ethyl acetate $(50 \mathrm{~mL})$. The aqueous phase was extracted with ethyl acetate $(50 \mathrm{~mL})$, and the combined organics were dried over magnesium sulfate. Solvent was evaporated and the residue was purified by flash chromatography (10:10:80 to 15:15:70 ethyl acetate:dichloromethane:hexanes eluent) to provide aldol adduct (+)-17 (6.01 g, 96\% yield) as a colorless oil: $\mathrm{R}_{\mathrm{F}} \quad 0.61 \quad(50: 25: 25$ hexanes:dichloromethane eluent); ${ }^{1} \mathrm{H}$ NMR (300 MHz, $\left.\mathrm{C}_{6} \mathrm{D}_{6}\right) \square 7.92-7.89$ (comp m, 2H), 6.93$6.90(\mathrm{~m}, 3 \mathrm{H}), 4.52(\mathrm{dq}, J=6.6,2.0 \mathrm{~Hz}, 1 \mathrm{H}), 4.12(\mathrm{~d}, J=2.4 \mathrm{~Hz}, 1 \mathrm{H}), 4.08-3.90$ (comp m, 2H), $3.30(\mathrm{~d}, J=17.0 \mathrm{~Hz}, 1 \mathrm{H}), 2.47(\mathrm{~d}, J=17.0 \mathrm{~Hz}, 1 \mathrm{H}), 1.62(\mathrm{~s}, 3 \mathrm{H}), 1.49(\mathrm{~s}, 3 \mathrm{H}), 1.33(\mathrm{~s}, 3 \mathrm{H})$, $0.96(\mathrm{t}, J=7.0 \mathrm{~Hz}, 3 \mathrm{H}), 0.69(\mathrm{~d}, J=6.6 \mathrm{~Hz}, 3 \mathrm{H}) ;{ }^{13} \mathrm{C} \mathrm{NMR}\left(75 \mathrm{MHz}, \mathrm{CDCl}_{3}\right) \square 173.9,140.6$, 133.2, 129.1, 128.6, 99.8, 74.9, 72.8, 72.0, 61.0, 42.9, 31.2, 28.8, 24.4, 22.5, 14.4; IR (NaCl/film) 3480, 2986, 1710, 1447, 1346, $1204 \mathrm{~cm}^{-1}$; HRMS (FAB) $\mathrm{m} / z$ calc'd for $\left[\mathrm{C}_{18} \mathrm{H}_{27} \mathrm{NO}_{6} \mathrm{~S}+\mathrm{H}\right]^{+}$: 386.1637 , found $386.1637 ;[\square]_{\mathrm{D}}^{26}+64.0^{\circ}(\mathrm{c}=2.00$, acetone $)$.

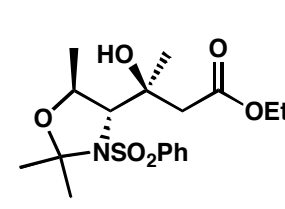

$(+)-17$

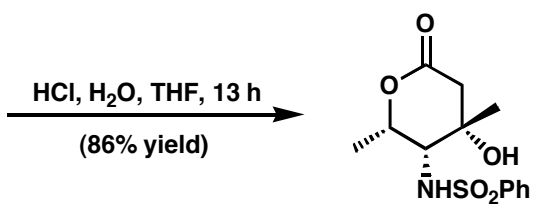

$(-)-S / 3$

Lactone (-)-SI3. A solution of aldol adduct (+)-17 (0.467g, $1.21 \mathrm{mmol})$ in tetrahydrofuran (12 $\mathrm{mL})$ was acidified with aqueous hydrochloric acid $(0.242 \mathrm{~mL}, 0.242 \mathrm{mmol})$. After $13 \mathrm{~h}$, the reaction was quenched with saturated aqueous sodium bicarbonate $(50 \mathrm{~mL})$, extracted with ethyl acetate $(2 \times 30 \mathrm{~mL})$, and dried over sodium sulfate. Solvent was evaporated and the residue was purified by flash chromatography (25:25:50 to 30:30:40 acetone:dichloromethane:hexanes eluent) to afford lactone (-)-SI3 (0.312 g, 86\% yield) as white solids. Crystals of sufficient quality for X-ray analysis of lactone (+)-SI3 (prepared in an analogous method) were grown from dichloromethane by slow evaporation (uncorrected mp. $164-165{ }^{\circ} \mathrm{C}$ ): $\mathrm{R}_{\mathrm{F}}$ 0.20 (50:25:25 hexanes:dichloromethane:acetone eluent); ${ }^{1} \mathrm{H} \mathrm{NMR}\left(300 \mathrm{MHz}\right.$, acetone- $\mathrm{d}_{6}$ ) $\square$ 8.01-7.90 (comp m, 2H), 7.68-7.56 (comp m, 3H), $4.61(\mathrm{dq}, J=6.6,4.5 \mathrm{~Hz}, 1 \mathrm{H}), 3.66(\mathrm{~d}, J=4.0 \mathrm{~Hz}, 1 \mathrm{H}), 2.76(\mathrm{~d}$, $J=16.0 \mathrm{~Hz}, 1 \mathrm{H}), 2.50(\mathrm{~d}, J=16.0 \mathrm{~Hz}, 1 \mathrm{H}), 1.20(\mathrm{~d}, J=6.6 \mathrm{~Hz}, 3 \mathrm{H}), 1.08(\mathrm{~s}, 3 \mathrm{H}) ;{ }^{13} \mathrm{C} \mathrm{NMR}$ $\left(75 \mathrm{MHz}, \mathrm{CDCl}_{3}\right) \square 171.8,140.7,133.2,129.4,127.3,76.0,69.9,59.3,43.2,27.5,16.6$; IR (NaCl/film) 3496, 3289, 2996, 1738, 1448, $1337 \mathrm{~cm}^{-1}$; HRMS (FAB) $\mathrm{m} / z$ calc'd for

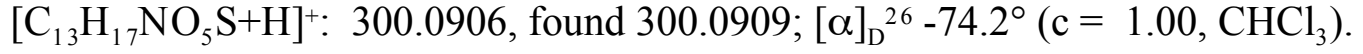


Crystal Structure of (+)-SI3.

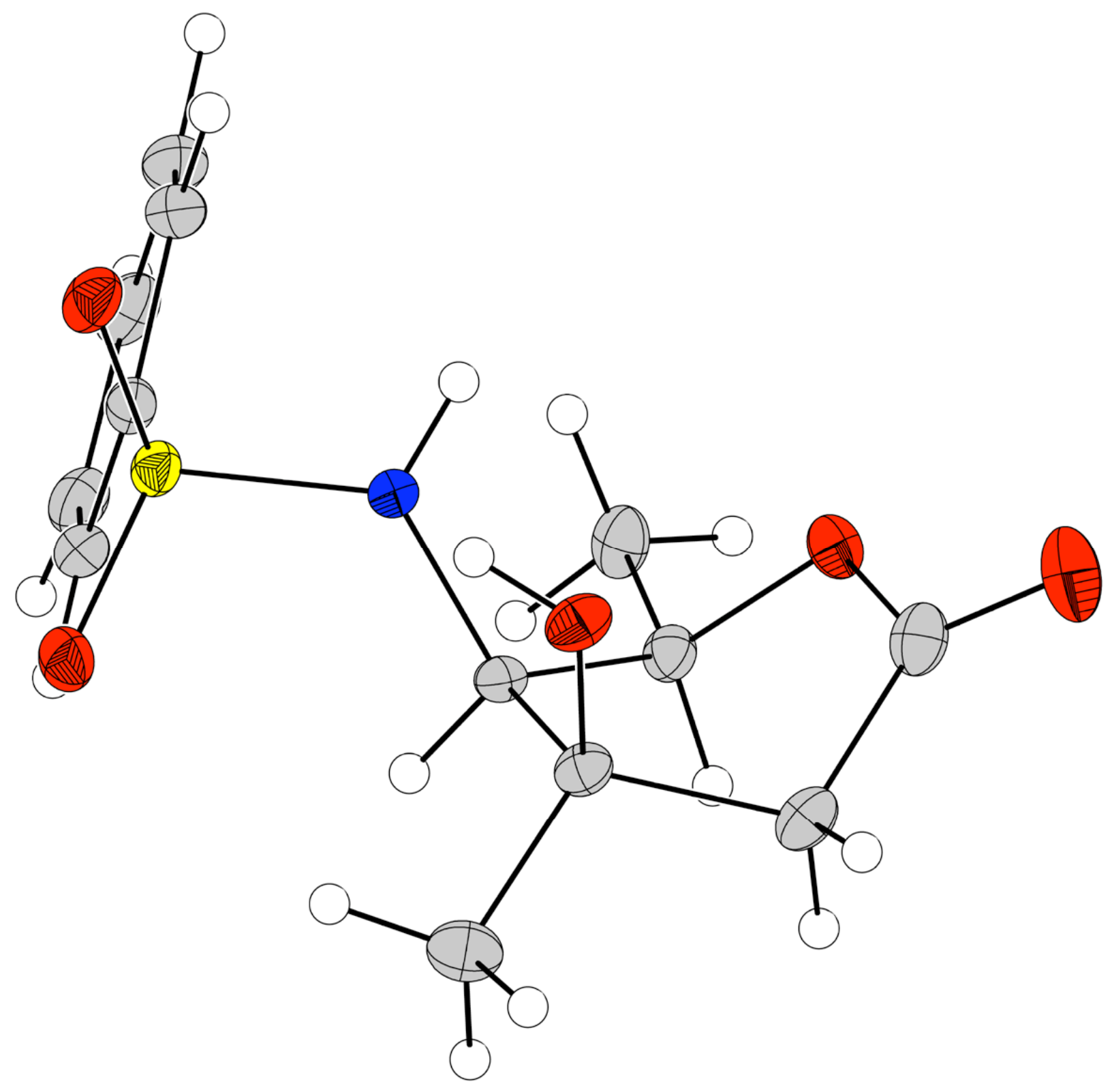


Table 1. Crystal data and structure refinement for (+)-SI3 (CCDC 217756).

Empirical formula

Formula weight

Crystal Habit

Crystal size

Crystal color

Preliminary Photos

Type of diffractometer

Wavelength

Data Collection Temperature

q range for 21790 reflections used

in lattice determination

Unit cell dimensions

Volume

Z

Crystal system

Space group

Density (calculated)

$\mathrm{F}(000)$

Data collection program

q range for data collection

Completeness to $\mathrm{q}=28.28^{\circ}$

Index ranges

Data collection scan type

Data reduction program

Reflections collected

Independent reflections

Absorption coefficient

Absorption correction

Max. and min. transmission (predicted)
$\mathrm{C}_{13} \mathrm{H}_{17} \mathrm{NO}_{5} \mathrm{~S}$

299.34

Prism

$0.35 \times 0.31 \times 0.26 \mathrm{~mm}^{3}$

Colorless

\section{Data Collection}

Rotation

Bruker SMART 1000

$0.71073 \AA \mathrm{MoKa}$

100(2) K

2.77 to $28.06^{\circ}$

$\mathrm{a}=8.0871(4) \AA$

$\mathrm{b}=8.2042(4) \AA$

$\mathrm{c}=20.6350(10) \AA$

1369.09(12) $\AA^{3}$

4

Orthorhombic

P212121

$1.452 \mathrm{Mg} / \mathrm{m}^{3}$

632

Bruker SMART v5.054

1.97 to $28.28^{\circ}$

$96.1 \%$

$-10 \leq \mathrm{h} \leq 10,-10 \leq \mathrm{k} \leq 10,-26 \leq 1 \leq 26$

$\square$ scans at $7 \square$ settings

Bruker SAINT v6.022

27404

$3217\left[\mathrm{R}_{\mathrm{int}}=0.0507\right]$

$0.255 \mathrm{~mm}^{-1}$

None

0.9366 and 0.9159 
Table 1 (cont.)

\section{Structure solution and Refinement}

Structure solution program

Primary solution method

Secondary solution method

Hydrogen placement

Structure refinement program

Refinement method

Data / restraints / parameters

Treatment of hydrogen atoms

Goodness-of-fit on $\mathrm{F}^{2}$

Final $\mathrm{R}$ indices $[\mathrm{I}>2 \square(\mathrm{I}), 3121$ reflections]

$\mathrm{R}$ indices (all data)

Type of weighting scheme used

Weighting scheme used

Max shift/error

Average shift/error

Absolute structure parameter

Largest diff. peak and hole
SHELXS-97 (Sheldrick, 1990)

Direct methods

Difference Fourier map

Difference Fourier map

SHELXL-97 (Sheldrick, 1997)

Full matrix least-squares on $\mathrm{F}^{2}$

3217 / 0 / 249

Unrestrained

2.819

$\mathrm{R} 1=0.0288, w \mathrm{R} 2=0.0590$

$\mathrm{R} 1=0.0298, w \mathrm{R} 2=0.0591$

Sigma

$\mathrm{w}=1 / \square^{2}\left(\mathrm{Fo}^{2}\right)$

0.001

0.000

$0.02(5)$

0.449 and -0.350 e. $\AA^{-3}$

\section{Special Refinement Details}

Refinement of $\mathrm{F}^{2}$ against ALL reflections. The weighted R-factor $(w \mathrm{R})$ and goodness of fit (S) are based on $\mathrm{F}^{2}$, conventional R-factors (R) are based on F, with $\mathrm{F}$ set to zero for negative $F^{2}$. The threshold expression of $F^{2}>2 \square\left(F^{2}\right)$ is used only for calculating R-factors(gt) etc. and is not relevant to the choice of reflections for refinement. R-factors based on $\mathrm{F}^{2}$ are statistically about twice as large as those based on F, and R-factors based on ALL data will be even larger.

All esds (except the esd in the dihedral angle between two 1.s. planes) are estimated using the full covariance matrix. The cell esds are taken into account individually in the estimation of esds in distances, angles and torsion angles; correlations between esds in cell parameters are only used when they are defined by crystal symmetry. An approximate (isotropic) treatment of cell esds is used for estimating esds involving 1.s. planes. 


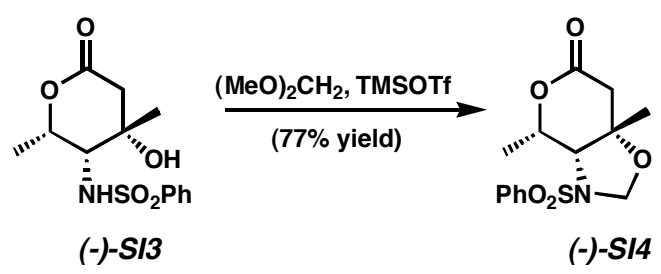

Oxazolidine (-)-SI4. To a suspension of lactone (-)-SI3 (2.92 g, $9.75 \mathrm{mmol})$ in dimethoxymethane $(49 \mathrm{~mL})$ at $0{ }^{\circ} \mathrm{C}$ was added trimethylsilyltriflate $(5.3 \mathrm{~mL}, 29 \mathrm{mmol})$ dropwise over $3 \mathrm{~min}$. After $20 \mathrm{~min}$, the reaction was quenched with saturated aqueous sodium bicarbonate $(100 \mathrm{~mL})$. The organic phase was separated and the aqueous phase was extracted with ethyl acetate $(75 \mathrm{~mL})$. The combined organics were dried over magnesium sulfate and solvent was evaporated. The residue was purified by flash chromatography (15:15:70 to 30:30:40 acetone:dichloromethane:hexanes eluent) to provide oxazolidine (-)-SI4 (2.34 g, 77\% yield) as a white solid: $\mathrm{R}_{\mathrm{F}} 0.46$ (50:25:25 hexanes:dichloromethane:acetone eluent); ${ }^{1} \mathrm{H}$ NMR $(300 \mathrm{MHz}$, $\mathrm{CDCl}_{3}$ ) $\square 7.95-7.90$ (comp m, 2H), 7.75-7.58 (comp m, 3H), 5.23 (d, $\left.J=7.2 \mathrm{~Hz}, 1 \mathrm{H}\right), 4.69$ (d, $J$ $=7.2 \mathrm{~Hz}, 1 \mathrm{H}), 4.49(\mathrm{dq}, J=6.3,2.7 \mathrm{~Hz}, 1 \mathrm{H}), 3.80(\mathrm{~d}, J=2.7 \mathrm{~Hz}, 1 \mathrm{H}), 2.74(\mathrm{~d}, J=16.0 \mathrm{~Hz}$, $1 \mathrm{H}), 2.54(\mathrm{~d}, J=16.0 \mathrm{~Hz}, 1 \mathrm{H}), 1.61(\mathrm{~d}, J=6.3 \mathrm{~Hz}, 3 \mathrm{H}), 0.84(\mathrm{~s}, 3 \mathrm{H}) ;{ }^{13} \mathrm{C} \mathrm{NMR}(75 \mathrm{MHz}$, $\left.\mathrm{CDCl}_{3}\right) \square$ 170.3, 137.8, 134.1, 129.8, 128.3, 82.0, 81.7, 75.0, 65.2, 40.9, 25.6, 17.3; IR $(\mathrm{NaCl} / \mathrm{film}) 3430,2902,1765,1446 \mathrm{~cm}^{-1}$; HRMS (FAB) $\mathrm{m} / z$ calc'd for $\left[\mathrm{C}_{14} \mathrm{H}_{17} \mathrm{NO}_{5} \mathrm{~S}+\mathrm{H}\right]^{+}$: 312.0906, found 312.0909; [ []$_{\mathrm{D}}{ }^{25}-151.0^{\circ}\left(\mathrm{c}=1.00, \mathrm{CHCl}_{3}\right)$.

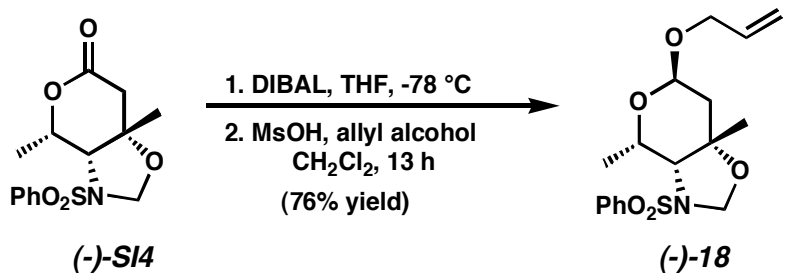

Bicycle (-)-18. A solution of oxazolidine (-)-SI4 (1.94 g, $6.23 \mathrm{mmol})$ in tetrahydrofuran (62 $\mathrm{mL})$ was cooled to $-78{ }^{\circ} \mathrm{C}$, and diisobutylaluminum hydride $(2.2 \mathrm{~mL}, 12 \mathrm{mmol})$ was added dropwise over $1 \mathrm{~min}$. After $30 \mathrm{~min}$, the reaction was quenched with aqueous Rochelle's salt $(100 \mathrm{~mL}, 1$ M). Organics were extracted with ethyl acetate $(2 \times 50 \mathrm{~mL})$, dried over magnesium sulfate, and concentrated. The residue was further dried by azeotropic removal of water with benzene. The crude residue was dissolved in dichloromethane $(62 \mathrm{~mL})$ followed by the addition of allyl alcohol $(6.35 \mathrm{~mL}, 93.4 \mathrm{mmol})$ and methanesulfonic acid $(0.81 \mathrm{~mL}, 1.2 \mathrm{mmol})$. After $18 \mathrm{~h}$, the reaction was quenched with saturated aqueous sodium bicarbonate $(100 \mathrm{~mL})$. Organics were extracted with dichloromethane $(50 \mathrm{~mL})$, dried over sodium sulfate, and concentrated under reduced pressure. The residue was purified by flash chromatography (10:90 to 15:85 ethyl acetate:hexanes eluent) to afford bicycle (-)-18 (1.67 g, 76\% yield) as a colorless oil: $\mathrm{R}_{\mathrm{F}} 0.17$ (85:15 hexanes:ethyl acetate eluent); ${ }^{1} \mathrm{H}$ NMR $\left(300 \mathrm{MHz}, \mathrm{CDCl}_{3}\right) \square 7.91-7.87$ (comp $\left.\mathrm{m}, 2 \mathrm{H}\right)$, 7.65-7.51 (comp m, 3H), $5.87(\mathrm{~m}, 1 \mathrm{H}), 5.25$ (appt. ddd, $J=17.1,3.3,1.8 \mathrm{~Hz}, 1 \mathrm{H}), 5.29-5.12$ (comp m, 2H), $4.84(\mathrm{dd}, J=8.1,6.0 \mathrm{~Hz}, 1 \mathrm{H}), 4.81(\mathrm{~d}, J=5.7 \mathrm{~Hz}, 1 \mathrm{H}), 4.20$ (ddt, $J=13.2,5.7$, $1.8 \mathrm{~Hz}, 1 \mathrm{H}), 4.04(\mathrm{dq}, J=6.6,2.7 \mathrm{~Hz}, 1 \mathrm{H}), 3.96(\mathrm{ddt}, J=11.7,5.1,1.2 \mathrm{~Hz}, 1 \mathrm{H}), 3.53(\mathrm{~d}, J=$ $2.4 \mathrm{~Hz}, 1 \mathrm{H}), 2.17(\mathrm{dd}, J=15.6,6.3 \mathrm{~Hz}, 1 \mathrm{H}), 1.64(\mathrm{dd}, J=15.3,8.4 \mathrm{~Hz}, 1 \mathrm{H}), 1.34(\mathrm{~d}, J=6.6$ 
$\mathrm{Hz}, 3 \mathrm{H}), 0.65$ (s, 3H); ${ }^{13} \mathrm{C}$ NMR $\left(75 \mathrm{MHz}, \mathrm{CDCl}_{3}\right) \square 138.7,134.8,133.6,129.5,128.1,117.1$, 95.9, 81.4, 81.0, 68.4, 65.7, 65.6, 37.8, 26.3, 17.4; IR (NaCl/film) 2981, 1447, 1353, $1166 \mathrm{~cm}^{-1}$; HRMS (FAB) $m / z$ calc'd for $\left[\mathrm{C}_{17} \mathrm{H}_{23} \mathrm{NO}_{5} \mathrm{~S}+\mathrm{H}\right]^{+}: 354.1375$, found 354.1373 ; [ []$_{\mathrm{D}}{ }^{26}-140.5^{\circ}(\mathrm{c}=$ $\left.1.00, \mathrm{CHCl}_{3}\right)$.

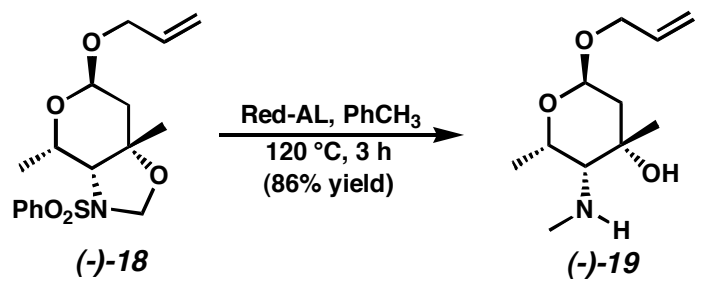

Glycoside (-)-19. To a solution of bicycle (-)-18 $(0.554 \mathrm{~g}, 1.57 \mathrm{mmol})$ in toluene $(16 \mathrm{~mL})$ was added Red-Al (3.53 mL, $11.7 \mathrm{mmol}, 65+\% \mathrm{w} / \mathrm{w}$ in toluene). The mixture was refluxed for $2.75 \mathrm{~h}$, cooled to $0{ }^{\circ} \mathrm{C}$, and Celite was added $(1.0 \mathrm{~g})$ followed by saturated aqueous sodium sulfate $(1.0$ $\mathrm{mL})$. The solution was allowed to warm to rt. The mixture was filtered, and solids were washed with ethyl acetate $(50 \mathrm{~mL})$ and brine $(15 \mathrm{~mL})$. The phases were separated and the aqueous phase was extracted with ethyl acetate $(2 \times 25 \mathrm{~mL})$. The combined organics were dried over sodium sulfate and concentrated under vacuum. Purification of the crude residue by flash chromatography (90:10:0.1:0.5 to 90:10:2:0.5 chloroform:ethyl acetate:methanol:triethylamine eluent) provided glycoside (-)-19 $(0.290 \mathrm{~g}, 86 \%$ yield $)$ as a colorless oil: $\mathrm{R}_{\mathrm{F}} 0.09$ (95:5 dichloromethane:methanol eluent); ${ }^{1} \mathrm{H}$ NMR $\left(300 \mathrm{MHz}, \mathrm{CDCl}_{3}\right) \square 5.88(\mathrm{~m}, 1 \mathrm{H}), 5.24$ (appt. ddd, $J=17.7,3.3,1.5 \mathrm{~Hz}, 1 \mathrm{H}$ ), 5.15 (appt. ddd, $J=10.5,3.3,1.8 \mathrm{~Hz}, 1 \mathrm{H}), 4.79$ (d, $J=4.2 \mathrm{~Hz}, 1 \mathrm{H}$ ), 4.16 (dq, $J=5.7,0.9 \mathrm{~Hz}, 1 \mathrm{H}$ ), 4.10 (ddt, $J=13.2,4.8,1.8 \mathrm{~Hz}, 1 \mathrm{H}$ ), 3.89 (ddt, $J=13.2,6.0,1.5$ $\mathrm{Hz}, 1 \mathrm{H}), 2.59$ (s, 3H), 2.02 (s, 1H), 1.72 (appt. d, $J=14.1 \mathrm{~Hz}, 1 \mathrm{H}), 1.59$ (dd, $J=13.8,4.5 \mathrm{~Hz}$, $1 \mathrm{H}), 1.41(\mathrm{~s}, 3 \mathrm{H}), 1.26(\mathrm{~d}, J=6.6 \mathrm{~Hz}, 3 \mathrm{H}) ;{ }^{13} \mathrm{C}$ NMR $\left(75 \mathrm{MHz}, \mathrm{CDCl}_{3}\right) \square$ 134.7, 116.6, 90.0, 68.2, 68.0, 67.7, 64.9, 40.0, 38.7, 26.1, 18.5; IR (NaCl/flim) 3345, 2932, $1118 \mathrm{~cm}^{-1}$; HRMS (FAB) $\mathrm{m} / z$ calc'd for $\left[\mathrm{C}_{11} \mathrm{H}_{20} \mathrm{NO}_{3}+\mathrm{H}\right]^{+}:$216.1600, found 216.1603; [0] ${ }_{\mathrm{D}}{ }^{26}-185.3^{\circ}(\mathrm{c}=1.00$, $\left.\mathrm{CHCl}_{3}\right)$.

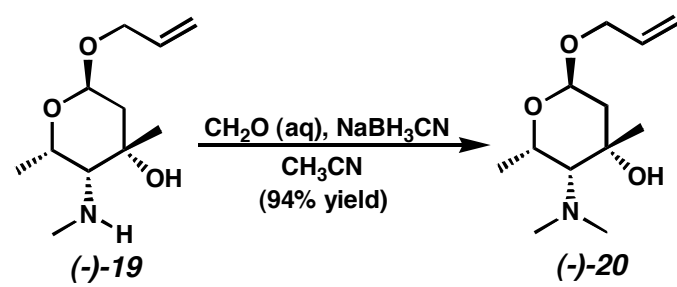

N, N-Dimethyl glycoside (-)-20. To glycoside (-)-19 (0.430 g, $2.00 \mathrm{mmol})$ in acetonitrile (20 $\mathrm{mL}$ ) was added sodium cyanoborohydride $(0.377 \mathrm{~g}, 6.00 \mathrm{mmol})$. After stirring for $5 \mathrm{~min}$, aqueous formaldehyde $(0.75 \mathrm{~mL}, 10 \mathrm{mmol}, 37 \% \mathrm{w} / \mathrm{w}$ in water) was added. The mixture was stirred vigorously for $2 \mathrm{~h}$, and the reaction was quenched with glacial acetic acid $(0.86 \mathrm{~mL})$. After concentrating the mixture under vacuum it was diluted with sodium hydroxide $(15 \mathrm{~mL}, 1 \mathrm{M})$ and brine $(40 \mathrm{~mL})$ then extracted with ethyl acetate $(3 \times 100 \mathrm{~mL})$. The organic layer was dried over sodium sulfate and concentrated. The residue was purified by flash chromatography 
(90:10:0.1:0.5 to $90: 10: 1.5: 0.5$ chloroform:ethyl acetate:methanol:triethylamine eluent) to yield dimethyl glycoside (-)-20 (0.429 $\mathrm{g}, 94 \%$ yield) as a colorless oil: $\mathrm{R}_{\mathrm{F}}$ 0.45 (90:10 chloroform:methanol eluent); ${ }^{1} \mathrm{H}$ NMR $\left(300 \mathrm{MHz}, \mathrm{CDCl}_{3}\right) \square 5.89$ (m, 1H), 5.35-5.10 (comp m, 2H), 5.14 (appt. dd, $J=10.5,1.8 \mathrm{~Hz}, 1 \mathrm{H}), 4.93$ (t, $J=2.7 \mathrm{~Hz}, 1 \mathrm{H}), 4.25$ (dq, $J=7.2,2.7 \mathrm{~Hz}$, 1H), 4.09 (ddt, $J=13.2,5.1,0.9 \mathrm{~Hz}, 1 \mathrm{H}), 3.91$ (ddt, $J=13.2,5.7,1.5 \mathrm{~Hz}, 1 \mathrm{H}), 2.68(\mathrm{~s}, 3 \mathrm{H})$, $2.21(\mathrm{~d}, J=2.7 \mathrm{~Hz}, 1 \mathrm{H}), 1.88(\mathrm{~d}, J=2.7 \mathrm{~Hz}, 2 \mathrm{H}), 1.43(\mathrm{~s}, 3 \mathrm{H}), 1.38(\mathrm{~d}, J=7.2 \mathrm{~Hz}, 3 \mathrm{H}) ;{ }^{13} \mathrm{C}$ NMR $\left(75 \mathrm{MHz}, \mathrm{CDCl}_{3}\right) \square$ 134.5, 116.3, 97.0, 69.4, 67.9, 66.2, 62.2, 45.0, 41.0, 29.5, 19.0; IR (NaCl/film) 3288, 2937, 1395, $1119 \mathrm{~cm}^{-1}$; HRMS (FAB) $m / z$ calc'd for $\left[\mathrm{C}_{12} \mathrm{H}_{22} \mathrm{NO}_{3}+\mathrm{H}\right]^{+}$: 230.1756, found 230.1754; [ $]_{\mathrm{D}}{ }^{24}-158.5^{\circ}(\mathrm{c}=1.00$, acetone $)$.

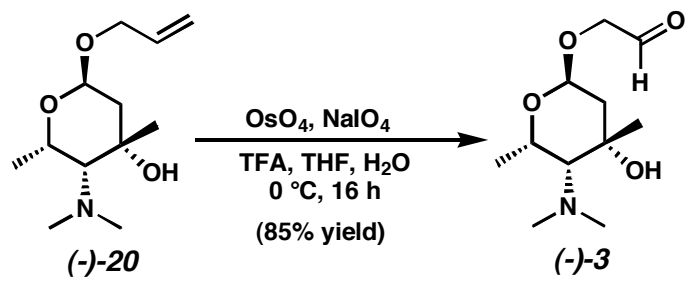

Glycosylated acetaldehyde (-)-3. A solution of glycoside (-)-20 (0.060 g, $0.26 \mathrm{mmol})$ in tetrahydrofuran $(4.8 \mathrm{~mL})$ and water $(0.48 \mathrm{~mL})$ was cooled to $0{ }^{\circ} \mathrm{C}$ and trifluoroacetic acid $(0.10$ $\mathrm{mL}, 1.3 \mathrm{mmol})$, osium tetroxide $(3.3 \mathrm{mg}, 0.013 \mathrm{mmol})$, and sodium periodate $(0.14 \mathrm{~g}, 0.65 \mathrm{mmol})$ were added. The mixture was stirred at $0{ }^{\circ} \mathrm{C}$ for $16 \mathrm{~h}$, and the reaction was quenched with potassium hydroxide $(0.13 \mathrm{~mL}, 10 \mathrm{M})$. After diluting with ethanol $(5 \mathrm{~mL})$, the mixture was filtered through a pad of silica gel, concentrated, and purified by preparative thin layer chromatography (15:85 methanol:chloroform eluent) to afford aldehyde (-)-3 as its trifluoroacetate salt (50.1 mg, 55\% yield) and aldehyde (-)-3 (18.4 mg, 30\% yield): $\mathrm{R}_{\mathrm{F}} 0.25$ (10:90 methanol:chloroform eluent); ${ }^{1} \mathrm{H}$ NMR $\left(300 \mathrm{MHz}, \mathrm{CD}_{3} \mathrm{OD}\right) \square 4.90$ (d, $\left.J=4.5 \mathrm{~Hz}, 1 \mathrm{H}\right), 4.62$ (appt. dt $J=8.4,5.7 \mathrm{~Hz}, 1 \mathrm{H}), 4.27$ (q, $J=7.2 \mathrm{~Hz}, 1 \mathrm{H}), 3.47(\mathrm{~m}, 1 \mathrm{H}), 3.38(\mathrm{~m}, 1 \mathrm{H}), 2.68(\mathrm{~s}$, $6 \mathrm{H}), 2.30(\mathrm{~s}, 1 \mathrm{H}), 1.88(\mathrm{dd}, J=13.8,4.5 \mathrm{~Hz}, 1 \mathrm{H}), 1.78(\mathrm{~d}, J=14.4 \mathrm{~Hz}, 1 \mathrm{H}), 1.39$ (s, 3H), 1.35 $(\mathrm{d}, J=7.2 \mathrm{~Hz}, 3 \mathrm{H}) ;{ }^{13} \mathrm{C} \mathrm{NMR}\left(75 \mathrm{MHz}, \mathrm{CD}_{3} \mathrm{OD}\right) \square 97.8,96.7,69.7,69.6,69.2,67.2,65.5$, 43.9, 40.4, 28.7, 18.0; IR (NaCl/film) 3290, 2937, 2836, 1682, $1127 \mathrm{~cm}^{-1}$; [ $]_{\mathrm{D}}{ }^{25}-122.5^{\circ}(\mathrm{c}=$ $0.45, \mathrm{CH}_{2} \mathrm{Cl}_{2}$ ).<smiles>COc1ccc(O)c(OC)c1C</smiles>

SI5

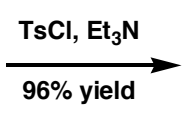

Tosyl Arene SI6. To a solution of SI5 $^{2}(10.15 \mathrm{~g}, 60.4 \mathrm{mmol})$ in dichloromethane $(60 \mathrm{~mL})$ were added triethylamine $(8.4 \mathrm{~mL}, 60.4 \mathrm{mmol})$ and $p$-toluenesulfonyl chloride $(11.5 \mathrm{~g}, 60.4 \mathrm{mmol})$. The reaction was maintained at $20{ }^{\circ} \mathrm{C}$ for $3.5 \mathrm{~h}$, after which acetonitrile $(80 \mathrm{~mL})$ and saturated aqueous sodium bicarbonate $(50 \mathrm{~mL})$ were added. After an addition hour the volatiles were removed in vacuo, and the residue was diluted with water $(350 \mathrm{~mL})$ and extracted into 
dichloromethane $(2 \times 250 \mathrm{~mL})$. The combined organics were dried over magnesium sulfate, concentrated, and purified by flash chromatography on silica gel (10:90 to 20:80 ethyl acetate:hexanes eluent) to provide SI6 (18.64 g, 96\% yield) as a white solid: $\mathrm{R}_{\mathrm{F}} 0.67$ (30:70 ethyl acetate:hexanes); ${ }^{1} \mathrm{H}$ NMR $\left(300 \mathrm{MHz}, \mathrm{CDCl}_{3}\right) \square 7.77(\mathrm{~d}, J=8.1 \mathrm{~Hz}, 2 \mathrm{H}), 7.30(\mathrm{~d}, J=7.8 \mathrm{~Hz}$, 2H), $6.87(\mathrm{~d}, J=9.3 \mathrm{~Hz}, 1 \mathrm{H}), 6.49(\mathrm{~d}, J=8.7 \mathrm{~Hz}, 1 \mathrm{H}), 3.77(\mathrm{~s}, 3 \mathrm{H}), 3.68(\mathrm{~s}, 3 \mathrm{H}), 2.43(\mathrm{~s}, 3 \mathrm{H})$, $2.06(\mathrm{~s}, 3 \mathrm{H}) ;{ }^{13} \mathrm{C} \mathrm{NMR}\left(75 \mathrm{MHz}, \mathrm{CDCl}_{3}\right) \square 156.9,151.2,145.1,136.4,133.2,129.6,128.4$, 121.4, 120.4, 105.2, 60.9, 55.8, 21.9, 9.3; IR (NaCl/film) 2941, 1597, 1483, 1371, $1177,1111 \mathrm{~cm}^{-}$ ${ }_{1}$; HRMS (FAB) calc'd for $\left[\mathrm{C}_{16} \mathrm{H}_{18} \mathrm{O}_{5} \mathrm{~S}+\mathrm{H}\right]^{+}: m / z$ 323.0953, found 323.0965.<smiles>COc1ccc([Se])c(OC)c1C</smiles>

SI6

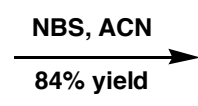

$S 17$

Aryl Bromide SI7. To a solution of SI6 $(1.0 \mathrm{~g}, 3.1 \mathrm{mmol})$ in acetonitrile $(10 \mathrm{~mL})$ was added $N$ bromosuccinimide $(580 \mathrm{mg}, 3.2 \mathrm{mmol})$. After $10.5 \mathrm{~h}$ the reaction was diluted with ethyl acetate $(150 \mathrm{~mL})$, washed with saturated aqueous sodium bicarbonate $(100 \mathrm{~mL})$, dried over sodium sulfate, concentrated, and filtered through a pad of silica gel (30:70 ethyl acetate:hexanes eluent) to provide SI7 (1.04 g, 84\% yield) as a white solid. $\mathrm{R}_{\mathrm{F}} 0.67$ (30:70 ethyl acetate:hexanes); ${ }^{1} \mathrm{H}$ NMR $\left(300 \mathrm{MHz}, \mathrm{CDCl}_{3}\right) \square 7.79(\mathrm{~d}, J=8.7 \mathrm{~Hz}, 2 \mathrm{H}), 7.35(\mathrm{~d}, J=7.8 \mathrm{~Hz}, 2 \mathrm{H}), 7.15(\mathrm{~s}, 1 \mathrm{H})$, $3.77(\mathrm{~s}, 3 \mathrm{H}), 3.69(\mathrm{~s}, 3 \mathrm{H}), 2.47(\mathrm{~s}, 3 \mathrm{H}), 2.19(\mathrm{~s}, 3 \mathrm{H}) ;{ }^{3} \mathrm{C}$ NMR $\left(75 \mathrm{MHz}, \mathrm{CDCl}_{3}\right) \square$ 154.7, $151.1,145.6,139.1,132.9,129.8,128.5,128.2,124.7,110.9,61.1,60.6,22.0$, 10.7; IR (NaCl/film) 2940, 1469, 1377, 1177, $554 \mathrm{~cm}^{-1}$; HRMS (FAB) calc'd for $\left[\mathrm{C}_{16} \mathrm{H}_{17} \mathrm{BrO}_{5} \mathrm{~S}+\mathrm{H}\right]^{+}: \mathrm{m} / \mathrm{z}$ 401.0058 , found 401.0045 .

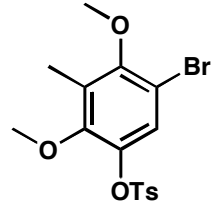

SI7

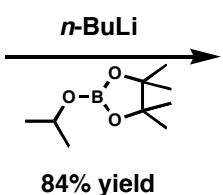

$84 \%$ yield

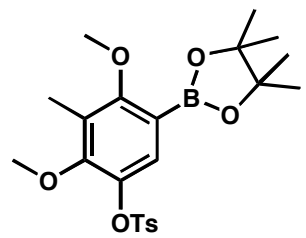

4

Arylboronic ester 4. To a chilled $\left(-78^{\circ} \mathrm{C}\right)$ solution of SI7 $(2.5 \mathrm{~g}, 6.23 \mathrm{mmol})$ in anhydrous diethyl ether $(62 \mathrm{~mL})$ was added $n$-butyllithium $(4.3 \mathrm{~mL}, 2.5 \mathrm{M}$ solution in hexanes, $10.9 \mathrm{mmol})$ dropwise over $5 \mathrm{~min}$. After $20 \mathrm{~min}$ a solution of 2-isopropoxy-4,4,5,5-tetramethyldioxaborolane $(2.5 \mathrm{~mL}, 12.5 \mathrm{mmol})$ in anhydrous diethyl ether $(41 \mathrm{~mL})$ was added via cannula over $5 \mathrm{~min}$. The reaction was then warmed to $-40{ }^{\circ} \mathrm{C}$ over $20 \mathrm{~min}$ and quenched with saturated aqueous ammonium chloride $(50 \mathrm{~mL})$. After warming to $20^{\circ} \mathrm{C}$, the mixture was diluted with water $(100$ $\mathrm{mL})$ and extracted with diethyl ether $(2 \times 100 \mathrm{~mL})$. The combined organics were dried over magnesium sulfate, concentrated, and purified by flash chromotography on silica gel (10:90 to 20:80 ethyl acetate:hexanes eluent) to provide 4 (2.35 g, 84\% yield) as a colorless oil: $\mathrm{R}_{\mathrm{F}} 0.65$ (30:70 ethyl acetate:hexanes); ${ }^{1} \mathrm{H}$ NMR $\left(300 \mathrm{MHz}, \mathrm{CDCl}_{3}\right) \square 7.80(\mathrm{~d}, J=8.4 \mathrm{~Hz}, 2 \mathrm{H}), 7.32(\mathrm{~d}, J$ 
$=8.4 \mathrm{~Hz}, 2 \mathrm{H}), 7.22(\mathrm{~s}, 1 \mathrm{H}), 3.75(\mathrm{~s}, 3 \mathrm{H}), 3.72(\mathrm{~s}, 3 \mathrm{H}), 2.46(\mathrm{~s}, 3 \mathrm{H}), 2.13(\mathrm{~s}, 3 \mathrm{H}), 1.32(\mathrm{~s}, 12 \mathrm{H})$; ${ }^{13} \mathrm{C}$ NMR $\left(75 \mathrm{MHz}, \mathrm{CDCl}_{3}\right) \square 163.3,154.0,145.0,138.2,133.0,129.5,128.3,128.1,126.2$, 83.6, 62.1 , 60.7, 24.8, 21.7, 9.5; IR (NaCl/film) 2979, 2935, 1597, 1358, 1178, $1143 \mathrm{~cm}^{-1}$; HRMS (FAB) calc'd for $\left[\mathrm{C}_{22} \mathrm{H}_{29} \mathrm{BO}_{7} \mathrm{~S}+\mathrm{H}\right]^{+}: \mathrm{m} / z$ 449.1805, found 449.1819 .
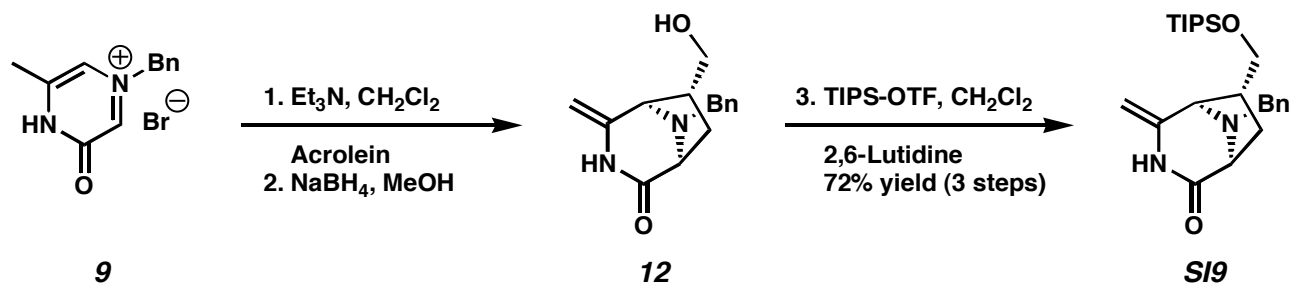

Silyl ether SI9 by racemic dipolar cycloaddition. To a suspension of $\mathbf{9}^{3}(10.0 \mathrm{~g}, 35.6 \mathrm{mmol})$ in dichloromethane $(119 \mathrm{~mL})$ was added triethylamine $(14.9 \mathrm{~mL}, 107 \mathrm{mmol})$, affording a clear solution, which was cooled to $-20{ }^{\circ} \mathrm{C}$ over $15 \mathrm{~min}$. Acrolein $(7.15 \mathrm{~mL}, 107 \mathrm{mmol})$ was then added dropwise over $5 \mathrm{~min}$. The reaction was maintained at $-20{ }^{\circ} \mathrm{C}$ for $74 \mathrm{~h}$, then warmed to 0 ${ }^{\circ} \mathrm{C}$ and diluted with methanol $(71 \mathrm{~mL})$. Sodium borohydride $(5.4 \mathrm{~g}, 142 \mathrm{mmol})$ was added in portions over $15 \mathrm{~min}$. After an additional $15 \mathrm{~min}$, the reaction was warmed to room temperature, quenched with saturated aqueous ammonium chloride $(200 \mathrm{~mL})$ and water $(300 \mathrm{~mL})$, and extracted into dichloromethane $(200 \mathrm{~mL}, 250 \mathrm{~mL})$. The combined organics were dried over sodium sulfate, concentrated, and dried aziotropically from benzene $(50 \mathrm{~mL})$ to provide racemic 12, which was used without further purification.

To a solution of crude $\mathbf{1 2}$ in dichloromethane $(71 \mathrm{~mL})$ were added 2,6-lutidine $(4.57 \mathrm{~mL}$, $39.2 \mathrm{mmol}$ ) and triisopropylsilyltrifluoromethanesulfonate $(10.5 \mathrm{~mL}, 39.2 \mathrm{mmol})$. After $75 \mathrm{~min}$ the reaction was quenched with water $(500 \mathrm{~mL})$ and extracted into dichloromethane $(100 \mathrm{~mL}, 150$ $\mathrm{mL}$ ). The combined organics were dried over sodium sulfate, concentrated, and purified by flash chromatography on silica gel (15:85 ethyl acetate:hexanes eluent) to provide racemic SI9 (10.65 g, 72\% yield) as a white solid: $\mathrm{R}_{\mathrm{F}} 0.41$ (30:70 ethyl acetate:hexanes); ${ }^{1} \mathrm{H}$ NMR (300 MHz, $\left.\mathrm{CDCl}_{3}\right) \square 7.35-7.21(\mathrm{comp} \mathrm{m}, 6 \mathrm{H}), 4.21(\mathrm{~s}, 1 \mathrm{H}), 4.08(\mathrm{~s}, 1 \mathrm{H}), 3.77(\mathrm{~d}, J=12.9 \mathrm{~Hz}, 1 \mathrm{H}), 3.71(\mathrm{~d}$, $J=13.2 \mathrm{~Hz}, 1 \mathrm{H}), 3.65(\mathrm{~s}, 1 \mathrm{H}), 3.63-3.54(\mathrm{comp} \mathrm{m}, 2 \mathrm{H}), 3.51(\mathrm{~d}, J=6.9 \mathrm{~Hz}, 1 \mathrm{H}), 2.34(\mathrm{app}$ ddd, $J=14.3,9.3,5.3 \mathrm{~Hz}, 1 \mathrm{H}$ ), 2.09 (dd, $J=13.4,9.5 \mathrm{~Hz}, 1 \mathrm{H}$ ), 1.69 (ddd, $J=13.2,7.2,5.2 \mathrm{~Hz}$, $1 \mathrm{H}), 1.02$ (br s, 21H); ${ }^{13} \mathrm{C}$ NMR $\left(75 \mathrm{MHz}, \mathrm{CDCl}_{3}\right) \square 172.4,142.7,138.4,128.8,128.3,127.2$, 90.6, 65.9, 63.2, 61.2, 52.5, 47.1, 32.3, 18.3, 12.2; IR (NaCl/film) 3195, 2943, 2866, 1687, 1650, $1105 \mathrm{~cm}^{-1}$; HRMS (FAB) calc'd for $\left[\mathrm{C}_{24} \mathrm{H}_{38} \mathrm{~N}_{2} \mathrm{O}_{2} \mathrm{Si}+\mathrm{H}\right]^{+}: \mathrm{m} / z$ 415.2781, found 415.2786. 

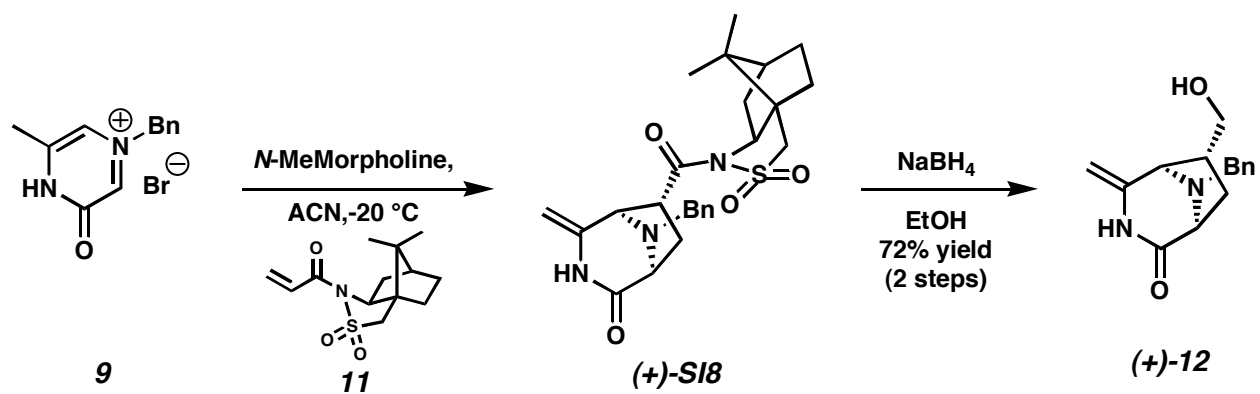

$(+)-12$

Diazabicycles (+)-SI8 and (+)-12. To a chilled $\left(-20^{\circ} \mathrm{C}\right)$ suspension of $9(421.5 \mathrm{mg}, 1.5 \mathrm{mmol})$ in acetonitrile $(15 \mathrm{~mL})$ were added $\mathbf{1 1}^{4}(485 \mathrm{mg}, 1.8 \mathrm{mmol})$ and $N$-methylmorpholine $(495 \square \mathrm{L}, 4.5$ mmol), which afforded a clear solution. The reaction was maintained at $-20{ }^{\circ} \mathrm{C}$ for $72 \mathrm{~h}$, after which ethanol $(15 \mathrm{~mL})$ and sodium borohydride $(570 \mathrm{mg}, 15 \mathrm{mmol})$ were added. The reaction was warmed to $20{ }^{\circ} \mathrm{C}$ for $4.5 \mathrm{~h}$, after which additional sodium borohydride $(570 \mathrm{mg}, 15 \mathrm{mmol})$ was added. After an addition $1.5 \mathrm{~h}$ the reaction was quenched with saturated aqueous ammonium chloride $(125 \mathrm{~mL})$ and extracted with ethyl acetate $(100 \mathrm{~mL}, 50 \mathrm{~mL})$. The organics were dried over sodium sulfate, concentrated, and purified by flash chromatography on silica gel (40:60 to 85:15 ethyl acetate:hexanes eluent) to provide $(+)-12(278 \mathrm{mg}, 72 \%$ yield, $94.7 \%$ ee $)$ as a colorless oil: $\mathrm{R}_{\mathrm{F}} 0.11$ (70:30 ethyl acetate:hexanes); ${ }^{1} \mathrm{H}$ NMR $\left(300 \mathrm{MHz}, \mathrm{CDCl}_{3}\right) \square 8.23$ (br s, $1 \mathrm{H}), 7.38-7.25$ (comp m, 5H), 4.32 (d, $J=1.2 \mathrm{~Hz}, 1 \mathrm{H}), 4.15$ (br s, 1H), 3.81 (d, $J=13.2 \mathrm{~Hz}$, $1 \mathrm{H}), 3.73(\mathrm{~m}, 1 \mathrm{H}), 3.72(\mathrm{~d}, J=12.9 \mathrm{~Hz}, 1 \mathrm{H}), 3.60(\mathrm{~d}, J=6.0 \mathrm{~Hz}, 1 \mathrm{H}), 3.57(\mathrm{~m}, 1 \mathrm{H}), 3.56(\mathrm{~s}$, 1H), 2.81 (br s, 1H), $2.37(\mathrm{~m}, 1 \mathrm{H}), 2.21(\mathrm{dd}, J=12.9,9.0 \mathrm{~Hz}, 1 \mathrm{H}), 2.09$ (ddd, $J=13.2,7.3,5.3$ $\mathrm{Hz}, 1 \mathrm{H}) ;{ }^{13} \mathrm{C} \mathrm{NMR}\left(75 \mathrm{MHz}, \mathrm{CDCl}_{3}\right) \square 171.7,141.7,137.7,129.0,128.7,127.8,91.2,66.2$, 63.2, 63.0, 52.6, 45.5, 32.9; IR (NaCl/film) 3354, 3210, 2936, 1676, $1317 \mathrm{~cm}^{-1}$; HRMS (FAB)

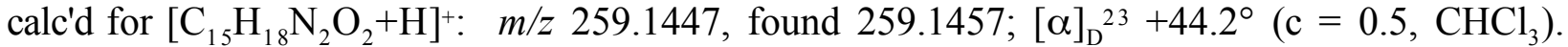
HPLC analysis (Chiracel AD column, 10:90 2-propanol:hexanes, $1 \mathrm{~mL} / \mathrm{min}, \square=254 \mathrm{~nm}$ ) showed the product to be of $94.7 \%$ ee $\left(\mathrm{t}_{\text {fast }}=17.95 \mathrm{~min}\right.$, major; $\mathrm{t}_{\text {slow }}=22.28 \mathrm{~min}$, minor $)$.

An analytical sample of the intermediate cycloadduct $(+)$-SI8 was prepared by flash chromatography on silica gel (20:20:60 acetone:dichloromethane:hexanes eluent): $\mathrm{R}_{\mathrm{F}} 0.33$ (25:25:50 acetone:dichloromethane:hexanes); $\left.{ }^{1} \mathrm{H} \mathrm{NMR} \mathrm{(300} \mathrm{MHz,} \mathrm{CDCl}_{3}\right) \square 7.46$ (br s, $\left.1 \mathrm{H}\right)$, 7.32-7.22 (comp m, 5H), 4.37 (d, $J=1.2 \mathrm{~Hz}, 1 \mathrm{H}), 4.32$ (d, $J=0.6 \mathrm{~Hz}, 1 \mathrm{H}), 3.94$ (d, $J=13.2$ Hz, 1H), 3.89 (dd, $J=8.1,4.8 \mathrm{~Hz}, 1 \mathrm{H}$ ), 3.75 (br d, $J=7.2 \mathrm{~Hz}, 1 \mathrm{H}$ ), 3.68 (br s, 1H), 3.59 (dd, $J$ $=8.7,4.2 \mathrm{~Hz}, 1 \mathrm{H}), 3.57(\mathrm{~d}, J=13.2 \mathrm{~Hz}, 1 \mathrm{H}), 3.41(\mathrm{~s}, 2 \mathrm{H}), 3.06(\mathrm{ddd}, J=13.2,7.8,3.9 \mathrm{~Hz}$, $1 \mathrm{H}), 2.15(\mathrm{dd}, J=13.5,9.0 \mathrm{~Hz}, 1 \mathrm{H}), 2.06(\mathrm{dd}, J=13.5,7.8 \mathrm{~Hz}, 1 \mathrm{H}), 1.96-1.79$ (comp m, 4H), 1.46-1.30 (comp m, 2H), 0.92 (s, 3H), 0.75 (s, 3H); ${ }^{3} \mathrm{C}$ NMR (75 MHz, $\left.\mathrm{CDCl}_{3}\right) \square$ 171.3, 170.9, 139.2, 138.1, 128.8, 128.5, 127.5, 93.8, 65.8, 63.4, 63.3, 53.3, 52.1, 49.1, 48.5, 47.9, 44.8, 38.5, 33.0, 31.3, 26.6, 20.7, 20.0; IR (NaCl/film) 3313, 3199, 2958, 1695, 1653, 1330, 1211, $1133 \mathrm{~cm}^{-1}$;

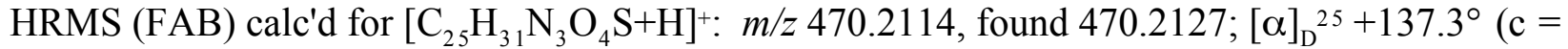
0.5 , acetone). 


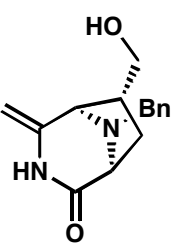

$(+)-12$

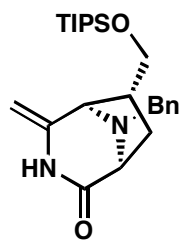

$(+)-S 19$

Silyl ether (+)-SI9. To a solution of $12(1.9 \mathrm{~g}, 7.36 \mathrm{mmol})$ in dichloromethane $(25 \mathrm{~mL})$ were added 2,6-lutidine $(1.03 \mathrm{~mL}, 8.83 \mathrm{mmol})$ and triisopropylsilyl-trifluoromethanesulfonate $(2.37$ $\mathrm{mL}, 8.83 \mathrm{mmol})$. After $15 \mathrm{~min}$ the reaction was quenched with water $(150 \mathrm{~mL})$ and extracted with dichloromethane $(50 \mathrm{~mL}, 30 \mathrm{~mL})$. The combined organics were dried over sodium sulfate, concentrated, and purified by flash chromatography on silica gel (15:85 to 30:70 ethyl acetate:hexanes eluent) to provide (+)-SI9 $\left(2.50 \mathrm{~g}, 82 \%\right.$ yield) as a colorless oil: $\mathrm{R}_{\mathrm{F}}$ 0.41 (30:70 ethyl acetate:hexanes); ${ }^{1} \mathrm{H}$ NMR $\left(300 \mathrm{MHz}, \mathrm{CDCl}_{3}\right) \square 7.35-7.21$ (comp m, 6H), 4.21 (s, 1H), $4.08(\mathrm{~s}, 1 \mathrm{H}), 3.77(\mathrm{~d}, J=12.9 \mathrm{~Hz}, 1 \mathrm{H}), 3.71(\mathrm{~d}, J=13.2 \mathrm{~Hz}, 1 \mathrm{H}), 3.65(\mathrm{~s}, 1 \mathrm{H}), 3.63-3.54$ (comp m, 2H), 3.51 (d, $J=6.9 \mathrm{~Hz}, 1 \mathrm{H}), 2.34$ (app ddd, $J=14.3,9.3,5.3 \mathrm{~Hz}, 1 \mathrm{H}), 2.09$ (dd, $J=13.4$, $9.5 \mathrm{~Hz}, 1 \mathrm{H}), 1.69$ (ddd, $J=13.2,7.2,5.2 \mathrm{~Hz}, 1 \mathrm{H}), 1.02$ (br s, 21H); ${ }^{13} \mathrm{C} \mathrm{NMR}(75 \mathrm{MHz}$, $\left.\mathrm{CDCl}_{3}\right) \square 172.4,142.7,138.4,128.8,128.3,127.2,90.6,65.9,63.2,61.2,52.5,47.1,32.3,18.3$, 12.2; IR (NaCl/film) 3195, 2943, 2866, 1687, 1650, $1105 \mathrm{~cm}^{-1}$; HRMS (FAB) calc'd for $\left[\mathrm{C}_{24} \mathrm{H}_{38} \mathrm{~N}_{2} \mathrm{O}_{2} \mathrm{Si}+\mathrm{H}\right]^{+}: m / z$ 415.2781, found 415.2786; [ $]_{\mathrm{D}}{ }^{23}+25.7^{\circ}$ (c = 1.5, acetone).

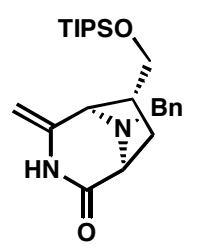

$(+)-S 19$

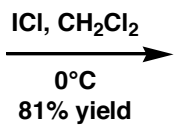

$81 \%$ yield

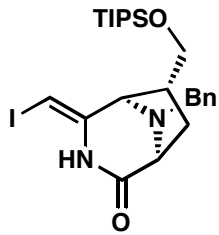

$(+)-5$

Iodoeneamide $(+)-5$. (Note: reaction run in a foil-wrapped flask to exclude light.) To a cooled $\left(0^{\circ} \mathrm{C}\right)$ solution of $(+)$-SI9 $(10.65 \mathrm{~g}, 25.7 \mathrm{mmol})$ in dichloromethane $(128 \mathrm{~mL})$ was added a cooled $\left(0{ }^{\circ} \mathrm{C}\right)$ solution of iodine monochloride $(6.26 \mathrm{~g}, 38.6 \mathrm{mmol})$ in dichloromethane $(38.6 \mathrm{~mL})$ via cannula over $5 \mathrm{~min}$. After $30 \mathrm{~min}$, additional iodine monochloride $(1.25 \mathrm{~g}, 7.7 \mathrm{mmol})$ in dichloromethane $(7.7 \mathrm{~mL}$ ) was added. After an additional $15 \mathrm{~min}$, the reaction was quenched with saturated aqueous sodium bisulfite $(100 \mathrm{~mL})$ followed by saturated aqueous sodium bicarbonate $(100 \mathrm{~mL})$. After stirring vigorously for $15 \mathrm{~min}$ (caution, gas evolution) the reaction was diluted with water $(150 \mathrm{~mL})$ and the phases were separated. The aqueous phase was extracted with dichloromethane $(150 \mathrm{~mL})$, and the combined organics were dried over sodium sulfate, concentrated, and purified by flash chromatography on silica gel (10:90 ethyl acetate:hexanes eluent) to provide $(+)-5(11.32 \mathrm{~g}, 82 \%$ yield $)$ as a colorless oil: $R_{F} 0.65(30: 70$ ethyl acetate:hexanes); ${ }^{1} \mathrm{H}$ NMR $\left(300 \mathrm{MHz} \mathrm{CDCl}_{3}\right) \square 7.37$ (br s, 1H), 7.33-7.24 (comp m, 5H), $4.98(\mathrm{~s}, 1 \mathrm{H}), 3.85(\mathrm{~s}, 1 \mathrm{H}), 3.75(\mathrm{~d}, J=13.2 \mathrm{~Hz}, 1 \mathrm{H}), 3.63(\mathrm{~d}, J=13.2 \mathrm{~Hz}, 1 \mathrm{H}), 3.64-3.54$ (comp $\mathrm{m}, 2 \mathrm{H}), 3.52(\mathrm{~d}, J=7.2 \mathrm{~Hz}, 1 \mathrm{H}), 2.33(\mathrm{~m}, 1 \mathrm{H}), 2.09(\mathrm{dd}, J=13.2,9.3 \mathrm{~Hz}, 1 \mathrm{H}), 1.69$ (ddd, $J=$ 13.2, 7.2, $5.5 \mathrm{~Hz}, 1 \mathrm{H}), 1.02$ (br s, 21H); ${ }^{13} \mathrm{C}$ NMR (75 MHz, $\mathrm{CDCl}_{3}$ ) $\square$ 171.1, 144.1, 137.7, 128.7, 128.5, 127.5, 65.7, 63.5, 62.8, 52.6, 46.6, 32.1, 18.3, 12.2; IR (NaCl/film) 2941, 2864, 
1703, 1632, 1280, 1104, $683 \mathrm{~cm}^{-1}$; HRMS (FAB) calc'd for $\left[\mathrm{C}_{24} \mathrm{H}_{37} \mathrm{IN}_{2} \mathrm{O}_{2} \mathrm{Si}+\mathrm{H}\right]^{+}: \mathrm{m} / z 541.1748$, found $541.1755 ;[\square]_{\mathrm{D}}{ }^{25}+47.3^{\circ}(\mathrm{c}=1.0$, acetone $)$.

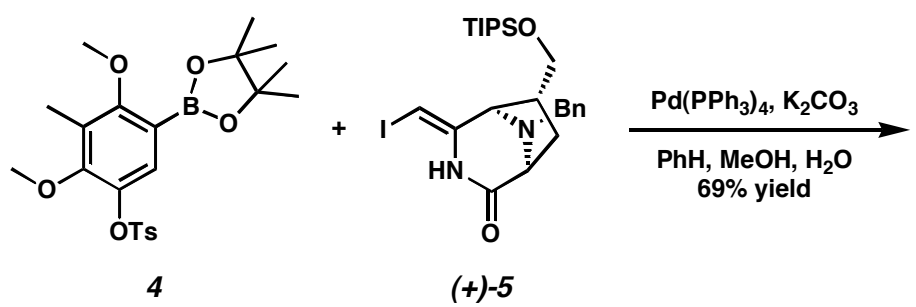

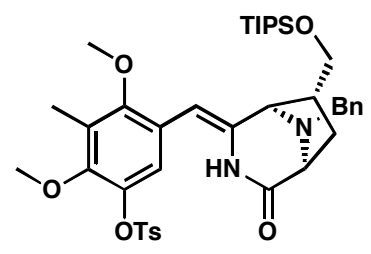

$(+)-13$

Aryl eneamide $(+)-13$. To a benzene $(138 \mathrm{~mL})$ solution of aryl boronic ester $4(3.1 \mathrm{~g}, 6.9 \mathrm{mmol})$ and iodoeneamide $(+)-5(3.75 \mathrm{~g}, 6.9 \mathrm{mmol})$ were added methanol $(27.6 \mathrm{~mL}), 2.0 \mathrm{M}$ aqueous potassium carbonate $(13.8 \mathrm{~mL}, 27.6 \mathrm{mmol}$ ) and tetrakis(triphenylphosphine)palladium (399 $\mathrm{mg}$, $345 \square \mathrm{mol}, 5 \mathrm{~mol} \%$ ). The reaction was deoxygenated by twice freezing under vacuum, flushing with argon, and melting. The reaction was then sealed under argon and heated to $70{ }^{\circ} \mathrm{C}$ for $3.5 \mathrm{~h}$. The mixture was then cooled to $23{ }^{\circ} \mathrm{C}$, diluted with water $(50 \mathrm{~mL})$ and saturated aqueous sodium chloride $(50 \mathrm{~mL})$, and extracted with ethyl acetate $(100 \mathrm{~mL})$ followed by dichloromethane $(100$ $\mathrm{mL}$ ). The combined organics were dried over sodium sulfate, concentrated, and purified by flash chromatography on silica gel (15:85 to 20:80 ethyl acetate:hexanes eluent) to provide $(+)-13$ (3.47 g, 69\% yield) as a yellow oil: $\mathrm{R}_{\mathrm{F}} 0.37$ (30:70 ethyl acetate:hexanes); ${ }^{1} \mathrm{H}$ NMR (300 MHz, $\left.\mathrm{CDCl}_{3}\right) \square 8.06$ (br s, 1H), $7.80(\mathrm{~d}, J=8.4 \mathrm{~Hz}, 2 \mathrm{H}), 7.35-7.19$ (comp m, 7H), 6.75 (s, 1H), 5.17 $(\mathrm{s}, 1 \mathrm{H}), 3.79(\mathrm{~d}, J=13.2 \mathrm{~Hz}, 1 \mathrm{H}), 3.72-3.58(\mathrm{comp} \mathrm{m}, 4 \mathrm{H}), 3.67(\mathrm{~s}, 3 \mathrm{H}), 3.64(\mathrm{~s}, 3 \mathrm{H}), 3.52(\mathrm{~d}, J$ $=7.2 \mathrm{~Hz}, 1 \mathrm{H}), 2.41(\mathrm{~s}, 3 \mathrm{H}), 2.35(\mathrm{~m}, 1 \mathrm{H}), 2.14(\mathrm{~s}, 3 \mathrm{H}), 2.09(\mathrm{dd}, J=12.6,9.0 \mathrm{~Hz}, 1 \mathrm{H}), 1.69$ (ddd, $J=12.6,7.2,6.0 \mathrm{~Hz}, 1 \mathrm{H}), 1.01$ (br s, 21H); ${ }^{13} \mathrm{C}$ NMR $\left(75 \mathrm{MHz}, \mathrm{CDCl}_{3}\right) \square$ 171.0, 153.9, $150.6,145.5,139.2,138.3,137.4,135.1,133.4,129.9,128.9,128.6,127.6,127.5,123.8,122.2$, 100.2, 66.0, 63.8, 62.8, 61.2, 60.3, 52.8, 47.4, 32.6, 22.1, 18.4, 12.3, 10.2; IR (NaCl/film) 2942, 2865, 1694, 1661, 1378, 1178, 1110, 993, $551 \mathrm{~cm}^{-1}$; HRMS (FAB) calc'd for $\left[\mathrm{C}_{40} \mathrm{H}_{54} \mathrm{~N}_{2} \mathrm{O}_{7} \mathrm{SSi}+\mathrm{H}\right]^{+}: m / z 735.3499$, found $735.3508 ;[\square]_{\mathrm{D}}{ }^{25}+40.1^{\circ}(\mathrm{c}=0.5$, acetone $)$.

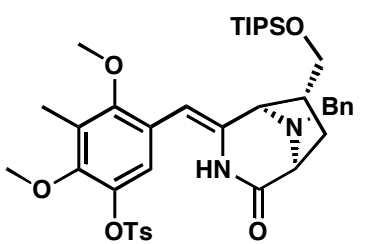

$(+)-13$

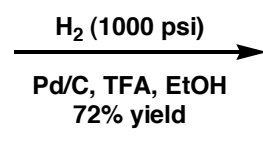

$72 \%$ yield

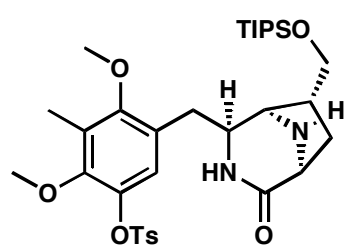

$(-)-14$

Ketopiperazine (-)-14. To an ethanol (58 mL) solution of (+)-13 (2.13 g, $2.90 \mathrm{mmol})$ were added trifluoroacetic acid $(4.5 \mathrm{~mL}, 58 \mathrm{mmol})$ and palladium on carbon $(10 \% \mathrm{w} / \mathrm{w}, 4.26 \mathrm{~g})$. The reaction was pressurized to 1000 psi with hydrogen in a stainless steel reaction vessel for $28 \mathrm{~h}$. The reaction was then diluted with water $(175 \mathrm{~mL})$, saturated aqueous sodium bicarbonate (175 $\mathrm{mL})$, and saturated aqueous sodium chloride $(175 \mathrm{~mL})$, and extracted with ethyl acetate $(150 \mathrm{~mL}$, $2 \times 100 \mathrm{~mL}$ ). The combined organics were dried over sodium sulfate, concentrated, and purified by flash chromatography (100 chloroform to 5:95 triethylamine:chloroform eluent) to provide ()-14 (1.345 g, 72\% yield) and a colorless oil: $\mathrm{R}_{\mathrm{F}} 0.52$ (10:90 methanol:chloroform); ${ }^{1} \mathrm{H}$ NMR 
$\left(300 \mathrm{MHz}, \mathrm{CDCl}_{3}\right) \square 7.80(\mathrm{~d}, J=8.4 \mathrm{~Hz}, 2 \mathrm{H}), 7.36(\mathrm{~d}, J=8.4 \mathrm{~Hz}, 2 \mathrm{H}), 6.76(\mathrm{~s}, 1 \mathrm{H}), 5.30(\mathrm{~s}$, 1H), 3.79-3.68 (comp m, 6H), 3.67 (s, 3H), 3.59 (app q, $J=8.5 \mathrm{~Hz}, 1 \mathrm{H}), 3.47$ (s, 1H), 2.69 (dd, $J=14.0,4.0 \mathrm{~Hz}, 1 \mathrm{H}), 2.63-2.49$ (comp m, 2H), 2.47 (s, 3H), 2.23-2.04 (comp m, 2H), 2.15 (s, $3 \mathrm{H}), 1.62$ (ddd, $J=12.8,6.6,6.6 \mathrm{~Hz}, 1 \mathrm{H}), 1.07$ (br s, $21 \mathrm{H}) ;{ }^{13} \mathrm{C} \mathrm{NMR}\left(75 \mathrm{MHz}, \mathrm{CDCl}_{3}\right) \square$ $173.5,156.1,150.9,145.5,138.9,133.2,129.9,128.5,127.3,125.7,122.2,66.3,61.0,60.8,60.3$, 60.0, 58.8, 38.6, 35.2, 33.0, 22.1, 18.4, 12.2, 10.3; IR (NaCl/film) 2943, 2866, 1678, 1483, 1377 , 1178, 1109, $1008 \mathrm{~cm}^{-1}$; HRMS (FAB) calc'd for $\left[\mathrm{C}_{33} \mathrm{H}_{50} \mathrm{~N}_{2} \mathrm{O}_{7} \mathrm{SSi}+\mathrm{H}\right]^{+}: \mathrm{m} / z \quad 647.3186$, found $647.3183 ;[\square]_{\mathrm{D}}^{23}-15.9^{\circ}(\mathrm{c}=1.0$, acetone $)$.

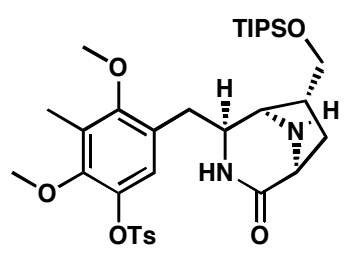

$(-)-14$

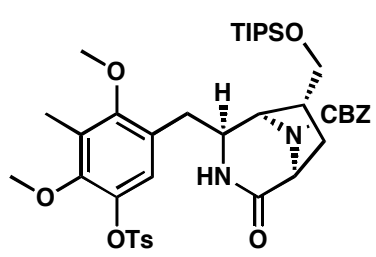

$(-)-S 110$

Carbamate (-)-SI10. To a solution of (-)-14 (700 mg, $1.08 \mathrm{mmol})$ in acetonitrile $(21.6 \mathrm{~mL})$ were added $N, N$-dimethylaminopyridine $(463 \mathrm{mg}, 3.8 \mathrm{mmol})$ and benzyl-chloroformate $(543 \square \mathrm{L}, 3.8$ $\mathrm{mmol})$. After $40 \mathrm{~min}$, the reaction was quenched into saturated aqueous ammonium chloride (150 $\mathrm{mL})$ and extracted into ethyl acetate $(3 \times 50 \mathrm{~mL})$. The combined organics were dried over sodium sulfate, concentrated, and purified by flash chromatography on silica gel (25:25:50 ethyl acetate:dichloromethane:hexanes eluent) to provide (-)-SI10 (794 mg, 94\% yield) as a white foam: $\mathrm{R}_{\mathrm{F}} 0.46$ (70:30 ethyl acetate:hexanes); ${ }^{1} \mathrm{H}$ NMR $\left(300 \mathrm{MHz}, \mathrm{CDCl}_{3}, 50^{\circ} \mathrm{C}\right) \square 7.78(\mathrm{~d}, J=$ 8.4 Hz, 2H), 7.35-7.23 (comp m, 7H), $6.74(\mathrm{~s}, 1 \mathrm{H}), 5.36(\mathrm{~s}, 1 \mathrm{H}), 5.17(\mathrm{~d}, J=12.3 \mathrm{~Hz}, 1 \mathrm{H}), 5.08$ $(\mathrm{d}, J=12.0 \mathrm{~Hz}, 1 \mathrm{H}), 4.49(\mathrm{~d}, J=6.6 \mathrm{~Hz}, 1 \mathrm{H}), 4.33(\mathrm{~s}, 1 \mathrm{H}), 3.93(\mathrm{~m}, 1 \mathrm{H}), 3.69(\mathrm{~s}, 3 \mathrm{H}), 3.64(\mathrm{~s}$, $3 \mathrm{H}), 3.62(\mathrm{~m}, 1 \mathrm{H}), 3.48(\operatorname{app~t}, J=9.5 \mathrm{~Hz}, 1 \mathrm{H}), 2.70(\mathrm{dd}, J=14.0,3.5 \mathrm{~Hz}, 1 \mathrm{H}), 2.65-2.54$ (comp m, 2H), $2.42(\mathrm{~s}, 3 \mathrm{H}), 2.15(\mathrm{dd}, J=12.6,8.7 \mathrm{~Hz}, 1 \mathrm{H}), 2.13(\mathrm{~s}, 3 \mathrm{H}), 1.65$ (ddd, $J=12.8$, 6.6, $6.0 \mathrm{~Hz}, 1 \mathrm{H}), 1.05$ (br s, 21H); ${ }^{13} \mathrm{C} \mathrm{NMR}\left(75 \mathrm{MHz}, \mathrm{CDCl}_{3}, 50{ }^{\circ} \mathrm{C}\right) \square 170.9,156.2,153.8$, $151.2,145.4,139.0,136.3,133.5,129.8,128.6,128.5,128.2,128.0,127.3,125.1,122.1,67.5$, $65.7,60.9,60.7,59.1,58.8,56.4,39.1,34.0,32.6,21.9,18.3,12.3,10.3$; IR (NaCl/film) 2943, 2866, 1709, 1685, 1378, 1178, $1109 \mathrm{~cm}^{-1}$; HRMS (FAB) calc'd for $\left[\mathrm{C}_{41} \mathrm{H}_{56} \mathrm{~N}_{2} \mathrm{O}_{9} \mathrm{SSi}+\mathrm{H}\right]^{+}: \mathrm{m} / z$

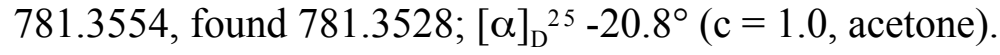

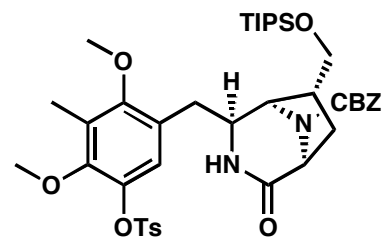

$(-)-S 110$

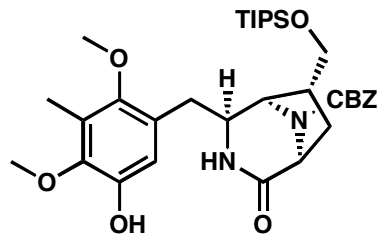

$(-)-2$

Phenol (-)-2. To a solution of (-)-SI10 (1 g, $1.28 \mathrm{mmol})$ in acetonitrile (25 $\mathrm{mL})$ was added potassium trimethylsilanoate $(90 \%$ grade, $1.82 \mathrm{~g}, 12.8 \mathrm{mmol})$. The reaction was maintained at 20 ${ }^{\circ} \mathrm{C}$ for $1.5 \mathrm{~h}$, quenched with saturated aqueous ammonium chloride $(25 \mathrm{~mL})$, and stirred vigorously for $10 \mathrm{~min}$. The mixture was diluted with saturated aqueous sodium chloride (150 
$\mathrm{mL})$, acidified to $\mathrm{pH} 5$ with concentrated hydrochloric acid, and extracted with ethyl acetate $(3 \mathrm{x}$ $100 \mathrm{~mL}$ ). The combined organics were dried over sodium sulfate, concentrated, and purified by flash chromatography on silica gel (50:50 to 80:20 ethyl acetate:hexanes eluent) to provide (-)-2 (735 mg, 92\% yield) as a white foam: $\mathrm{R}_{\mathrm{F}} 0.42$ (70:30 ethyl acetate:hexanes); ${ }^{1} \mathrm{H}$ NMR (300 $\left.\mathrm{MHz}, \mathrm{CDCl}_{3}, 50^{\circ} \mathrm{C}\right) \square 7.37-7.29$ (comp m, 5H), 6.59 (s, 1H), 6.03 (s, 1H), 5.66 (s, 1H), 5.19 (d, $J=12.3 \mathrm{~Hz}, 1 \mathrm{H}), 5.10(\mathrm{~d}, J=12.3 \mathrm{~Hz}, 1 \mathrm{H}), 4.52(\mathrm{~d}, J=6.6 \mathrm{~Hz}, 1 \mathrm{H}), 4.39(\mathrm{~s}, 1 \mathrm{H}), 4.05($ br s, $1 \mathrm{H}), 3.77$ (s, 3H), 3.69-3.61 (comp m, 4H), $3.52(\mathrm{~m}, 1 \mathrm{H}), 2.76(\mathrm{dd}, J=13.8,3.9 \mathrm{~Hz}, 1 \mathrm{H}), 2.71-$ 2.61 (comp m, 2H), 2.23 (s, 3H), $2.20(\mathrm{dd}, J=13.2,8.7 \mathrm{~Hz}, 1 \mathrm{H}), 1.67$ (ddd, $J=12.8,6.6,6.0$ $\mathrm{Hz}, 1 \mathrm{H}), 1.08$ (br s, 21H); ${ }^{13} \mathrm{C}$ NMR $\left(75 \mathrm{MHz}, \mathrm{CDCl}_{3}, 50{ }^{\circ} \mathrm{C}\right) \square 171.3,154.0,150.5,145.9$, $145.5,136.4,128.6,128.2,128.0,125.5,125.2,114.2,67.5,65.8,60.8,59.0,56.6,39.3,34.1$, 32.7, 18.3, 12.3, 10.2; IR (NaCl/film) 3306, 2943, 2865, 1709, 1679, 1457, 1418, 1307, $1112 \mathrm{~cm}^{-}$ ${ }^{1}$; HRMS (FAB) calc'd for $\left[\mathrm{C}_{34} \mathrm{H}_{50} \mathrm{~N}_{2} \mathrm{O}_{7} \mathrm{Si}+\mathrm{H}\right]^{+}: \mathrm{m} / z$ 627.3465, found 627.3469; [D] $]_{\mathrm{D}}{ }^{24}-30.5^{\circ}$ (c $=1.0$, acetone).

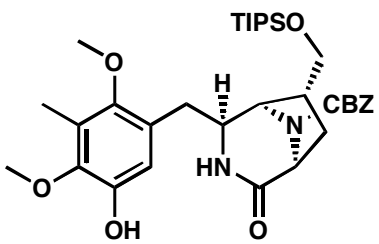

$(-)-2$

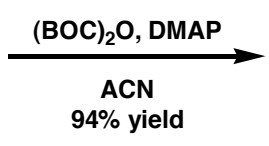

Activated lactam (-)-SI11. To a solution of (-)-2 (960 mg, $1.53 \mathrm{mmol})$ in acetonitrile (15.3 $\mathrm{mL})$ were added $N, N$-dimethylaminopyridine $(935 \mathrm{mg}, 7.66 \mathrm{mmol})$ and di-tert-butyl dicarbonate (1.67 $\mathrm{g}, 7.66 \mathrm{mmol})$. The reaction was maintained at $20{ }^{\circ} \mathrm{C}$ for $25 \mathrm{~min}$, diluted with water $(150 \mathrm{~mL})$, and extracted with ethyl acetate $(2 \times 75 \mathrm{~mL})$. The combined organics were dried over sodium sulfate, concentrated, and purified by flash chromatography on silica gel (10:90 to 20:80 ethyl acetate:hexanes) to provide (-)-SI11 (1.22 g, 96\% yield) as an off-white foam: $\mathrm{R}_{\mathrm{F}} 0.63$ (30:70 ethyl acetate:hexanes); ${ }^{1} \mathrm{H}$ NMR $\left(300 \mathrm{MHz}, \mathrm{CDCl}_{3}, 50^{\circ} \mathrm{C}\right) \square 7.40-7.22$ (comp m, 5H), 6.86 (s, $1 \mathrm{H}), 5.16(\mathrm{~d}, J=12.8 \mathrm{~Hz}, 1 \mathrm{H}), 5.04(\mathrm{~d}, J=12.8 \mathrm{~Hz}, 1 \mathrm{H}), 4.64(\operatorname{app~d}, J=6.6 \mathrm{~Hz}, 2 \mathrm{H}), 3.93(\mathrm{~d}$, $J=4.5 \mathrm{~Hz}, 1 \mathrm{H}), 3.81(\mathrm{~s}, 3 \mathrm{H}), 3.68(\mathrm{~s}, 3 \mathrm{H}), 3.61$ (br s, $1 \mathrm{H}), 3.28(\mathrm{dd}, J=9.3,7.8 \mathrm{~Hz}, 1 \mathrm{H}), 3.10$ $(\mathrm{dd}, J=13.7,4.4 \mathrm{~Hz}, 1 \mathrm{H}), 2.84-2.70$ (comp m, 2H), 2.21 (s, 3H), $2.17(\mathrm{dd}, J=13.8,8.7 \mathrm{~Hz}$, $1 \mathrm{H}), 2.05(\mathrm{~m}, 1 \mathrm{H}), 1.57(\mathrm{~s}, 9 \mathrm{H}), 1.54(\mathrm{~s}, 9 \mathrm{H}), 0.99$ (br s, 21H); ${ }^{13} \mathrm{C} \mathrm{NMR}\left(75 \mathrm{MHz}, \mathrm{CDCl}_{3}, 50\right.$ $\left.{ }^{\circ} \mathrm{C}\right) \square 169.8,155.2,153.4,152.4,151.8,150.1,140.7,136.3,128.6,128.1,127.9,126.2,124.8$, $121.2,84.1,83.4,79.4,67.4,65.8,60.7,60.1,57.1,38.5,32.9,30.6,28.6,28.2,28.0,18.2$, 12.2, 10.2; IR (NaCl/film) 2943, 2866, 1762, 1717, 1275, 1234, $1154 \mathrm{~cm}^{-1}$; HRMS (FAB) calc'd for $\left[\mathrm{C}_{44} \mathrm{H}_{66} \mathrm{~N}_{2} \mathrm{O}_{11} \mathrm{Si}+\mathrm{H}\right]^{+}: \mathrm{m} / z$ 827.4515, found 827.4498; [ []$_{\mathrm{D}}{ }^{23}-26.2^{\circ}\left(\mathrm{c}=1.0, \mathrm{CHCl}_{3}\right)$. 


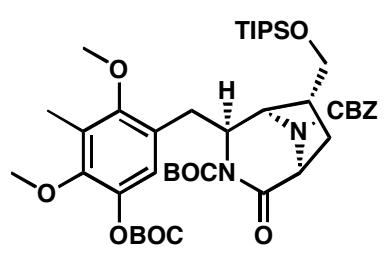

$(-)-S 111$

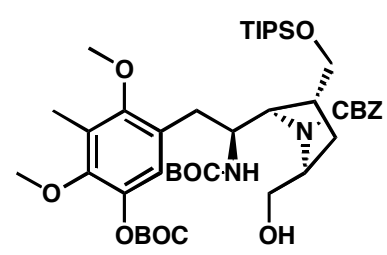

(-)-SI12

Protected aminotriol (-)-SI12. To a solution of (-)-SI11 (1.22 g, $1.47 \mathrm{mmol})$ in ethanol (14.7 $\mathrm{mL})$ was added sodium borohydride $(1.12 \mathrm{~g}, 29.5 \mathrm{mmol})$. The reaction was maintained at $20{ }^{\circ} \mathrm{C}$ for $1 \mathrm{~h} 45 \mathrm{~min}$, then quenched slowly (caution, gas evolution) with saturated aqueous ammonium chloride $(100 \mathrm{~mL})$, diluted with water $(20 \mathrm{~mL})$, and extracted with dichloromethane $(50 \mathrm{~mL}, 2 \mathrm{x}$ $25 \mathrm{~mL}$ ). The combined organics were dried over sodium sulfate, concentrated, and purified by flash chromatography and silica gel (25:75 to 35:65 ethyl acetate:hexanes eluent) to provide (-)SI12 (1.05 g, $86 \%$ yield) as a white foam: $\mathrm{R}_{\mathrm{F}} 0.27$ (30:70 ethyl acetate:hexanes); ${ }^{1} \mathrm{H}$ NMR (300 $\left.\mathrm{MHz}, \mathrm{CDCl}_{3}, 50^{\circ} \mathrm{C}\right) \square 7.43-7.29$ (comp m, 5H), 6.73 (s, 1H), 5.18 (s, 2H), 4.10 (m, 1H), 3.973.85 (comp m, 2H), 3.80 (dd, $J=11.6,2.9 \mathrm{~Hz}, 1 \mathrm{H}), 3.75(\mathrm{~s}, 3 \mathrm{H}), 3.63$ (dd, $J=11.7,6.6 \mathrm{~Hz}$, 1H), 3.59-3.47 (comp m, 5H), 2.84 (br d, $J=11.7 \mathrm{~Hz}, 1 \mathrm{H}$ ), 2.46 (br t, $J=11.6 \mathrm{~Hz}, 1 \mathrm{H}$ ), 2.35 $(\mathrm{m}, 1 \mathrm{H}), 2.20(\mathrm{~s}, 3 \mathrm{H}), 2.02-1.86(\mathrm{comp} \mathrm{m}, 2 \mathrm{H}), 1.56(\mathrm{~s}, 9 \mathrm{H}), 1.26(\mathrm{~s}, 9 \mathrm{H}), 1.06($ br s, $21 \mathrm{H}) ;{ }^{13} \mathrm{C}$ NMR $\left(75 \mathrm{MHz}, \mathrm{CDCl}_{3}, 50{ }^{\circ} \mathrm{C}\right) \square 157.5,155.9,155.2,151.9,149.6,140.4,136.5,128.6,128.3$, $128.2,127.2,125.5,121.6,83.2,79.2,67.9,67.2,65.8,65.3,61.3,60.7,60.6,55.0,42.4,33.1$, 29.3, 28.5, 28.0, 18.3, 12.3, 10.1; IR (NaCl/film) 3353, 2943, 2866, 1761, 1698, 1275, 1233, $1156 \mathrm{~cm}^{-1}$; HRMS (FAB) calc'd for $\left[\mathrm{C}_{44} \mathrm{H}_{70} \mathrm{~N}_{2} \mathrm{O}_{11} \mathrm{Si}+\mathrm{H}\right]^{+}: \mathrm{m} / z$ 831.4828, found 831.4827; [ $]_{\mathrm{D}}{ }^{24}$ $-7.6^{\circ}(\mathrm{c}=1.0$, acetone $)$.

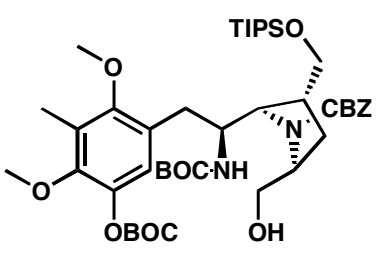

$(-)-S 112$
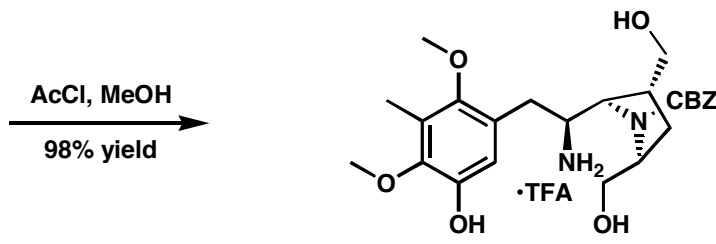

$(-)-15 \cdot T F A$

Aminotriol (-)-15. To a cooled $\left(0{ }^{\circ} \mathrm{C}\right)$ solution of (-)-SI12 (250 mg, $\left.300 \square \mathrm{mol}\right)$ in methanol (6 $\mathrm{mL})$ was added acetyl chloride $(427 \square \mathrm{L}, 6 \mathrm{mmol})$ dropwise over $30 \mathrm{sec}$. The reaction was warmed to $20{ }^{\circ} \mathrm{C}$ for $9 \mathrm{~h}$, concentrated, and purified by preparative HPLC to provide (-)-15 trifluoroacetate $\left(175 \mathrm{mg}, 98 \%\right.$ yield) as a colorless, highly viscous oil: $\mathrm{R}_{\mathrm{F}}$ 0.11 (10:90 methanol:chloroform); ${ }^{1} \mathrm{H}$ NMR $\left(300 \mathrm{MHz}, \mathrm{CD}_{3} \mathrm{OD}, 50^{\circ} \mathrm{C}\right) \square 7.32$ (br s, 5H), 6.63 (s, 1H), 5.12 (br s, 2H), 4.11-4.01 (comp m, 2H), $3.99(\operatorname{app~t,} J=3.0 \mathrm{~Hz}, 1 \mathrm{H}), 3.90$ (app td, $J=7.4,2.4 \mathrm{~Hz}$, $1 \mathrm{H}), 3.74(\mathrm{~s}, 3 \mathrm{H}), 3.64(\mathrm{~s}, 3 \mathrm{H}), 3.59-3.46$ (comp m, 3H), 2.92 (br s, 1H), 2.75 (m, 1H), 2.50 $(\mathrm{ddd}, J=13.8,6.3,3.7 \mathrm{~Hz}, 1 \mathrm{H}), 2.19(\mathrm{~s}, 3 \mathrm{H}), 2.17(\mathrm{dd}, J=15.3,7.8 \mathrm{~Hz}, 1 \mathrm{H}), 2.02(\mathrm{~m}, 1 \mathrm{H}) ;{ }^{13} \mathrm{C}$ NMR $\left(75 \mathrm{MHz}, \mathrm{DMSO}_{-}, \mathrm{d}_{6}{ }^{\circ} \mathrm{C}\right) \mathrm{154.7}$, 149.2, 145.8, 145.4, 136.3, 128.0, 127.4, 127.0, $124.0,123.3,115.2,66.1,63.0,62.1,60.9,59.9,59.1,58.5,54.6,30.3,28.4,9.2 ; \mathrm{IR}(\mathrm{NaCl} / \mathrm{film})$ 3272, 2946, 2896, 1694, 1674, 1418, 1204, $1134 \mathrm{~cm}^{-1}$; HRMS (FAB) calc'd for $\left[\mathrm{C}_{25} \mathrm{H}_{34} \mathrm{~N}_{2} \mathrm{O}_{7}+\mathrm{H}\right]^{+}: \mathrm{m} / z$ 475.2444, found 475.2445; [ $]_{\mathrm{D}}{ }^{24}-11.4^{\circ}$ (c $=0.48$, methanol). 


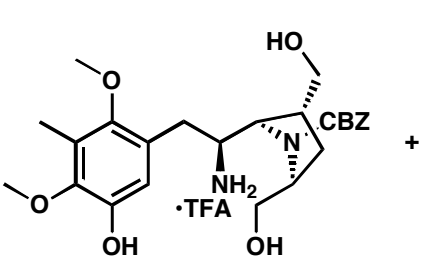

$(-)-15 \cdot T F A$

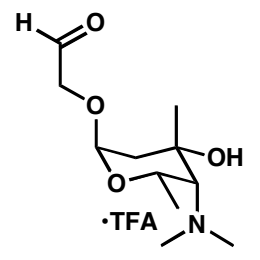

$(-)-3 \cdot T F A$

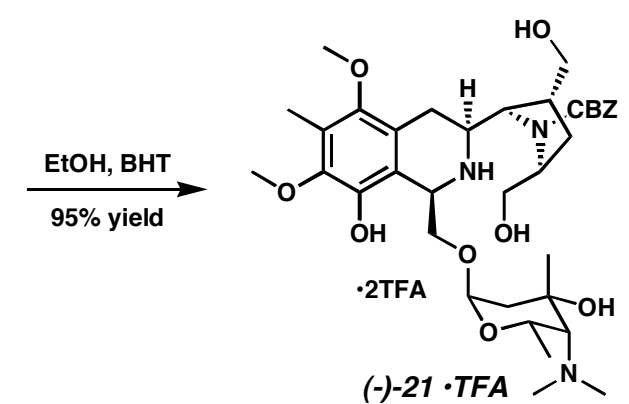

Tetrahydroisoquinoline (-)-21. To neat (-)-15 trifluoroacetate (50 mg, $85 \square \mathrm{mol})$ were added 2,6-di-tert-butyl-4-methyl phenol (9.3 mg, $42.5 \square \mathrm{mol})$ and a solution of (-)-3 trifluoroacetate (50 $\mathrm{mg}, 144.7 \square \mathrm{mol})$ in ethanol $(1.7 \mathrm{~mL})$. The reaction was sealed under argon in a foil-wrapped vial at $20{ }^{\circ} \mathrm{C}$. After $36 \mathrm{~h}$, additional (-)-3 (5 mg, $\left.21.6 \square \mathrm{mol}\right)$ was added. After $63 \mathrm{~h}$, the reaction was concentrated and purified by preparative HPLC to provide (-)-21 bis-trifluoroacetate (74 mg, 95\% yield) as a colorless, highly viscous oil: $\mathrm{R}_{\mathrm{F}} 0.27$ (10:90 methanol:chloroform); ${ }^{1} \mathrm{H}$ NMR $\left(300 \mathrm{MHz}, \mathrm{CD}_{3} \mathrm{OD}, 45^{\circ} \mathrm{C}\right) \mathrm{7} .43-7.32(\operatorname{comp~m}, 5 \mathrm{H}), 5.29(\mathrm{~d}, J=12.0 \mathrm{~Hz}, 1 \mathrm{H}), 5.21(\mathrm{~d}, J=$ $12.0 \mathrm{~Hz}, 1 \mathrm{H}), 5.12(\mathrm{~d}, J=3.3 \mathrm{~Hz}, 1 \mathrm{H}), 4.97(\mathrm{~s}, 1 \mathrm{H}), 4.51(\mathrm{br} \mathrm{d}, J=7.8 \mathrm{~Hz}, 1 \mathrm{H}), 4.18(\mathrm{~m}, 1 \mathrm{H})$, 4.02 (br d, $J=8.7 \mathrm{~Hz}, 1 \mathrm{H}), 3.83(\operatorname{app~d}, J=9.9 \mathrm{~Hz}, 1 \mathrm{H}), 3.80-3.57$ (comp m, 6H), 3.73 (s, 3H), $3.64(\mathrm{~s}, 3 \mathrm{H}), 3.36(\mathrm{~d}, J=6.6 \mathrm{~Hz}, 1 \mathrm{H}), 3.04(\mathrm{~s}, 6 \mathrm{H}), 3.01(\mathrm{~s}, 1 \mathrm{H}), 2.62-2.46$ (comp m, 2H), 2.21 (s, 3H), 2.13-2.01 (comp m, 3H), 1.93 (ddd, $J=21.9,11.3,10.8 \mathrm{~Hz}, 1 \mathrm{H}), 1.44$ (d, $J=6.9 \mathrm{~Hz}$, $3 \mathrm{H}), 1.19$ (s, 3H); ${ }^{3} \mathrm{C}$ NMR $\left(75 \mathrm{MHz}, \mathrm{CD}_{3} \mathrm{OD}, 50{ }^{\circ} \mathrm{C}\right) \square 159.5,150.1,146.8,144.4,137.4$, $129.7,129.4,128.9,126.0,124.0,115.5,98.1,72.1,69.5,67.9,66.8,64.9,64.5,63.9,63.5,61.7$, 61.3, 61.2, 57.5, 55.4, 44.8, 39.9, 30.8, 30.5, 21.9, 18.6, 10.0; IR (NaCl/film) 3307, 3064, 2945, $1682,1204,1180,1131 \mathrm{~cm}^{-1}$; HRMS (FAB) calc'd for $\left[\mathrm{C}_{36} \mathrm{H}_{53} \mathrm{~N}_{3} \mathrm{O}_{10}+\mathrm{H}\right]^{+}: \mathrm{m} / z 688.3809$, found $688.3835 ;[\square]_{\mathrm{D}}{ }^{26}-71.3^{\circ}(\mathrm{c}=0.5$, methanol).
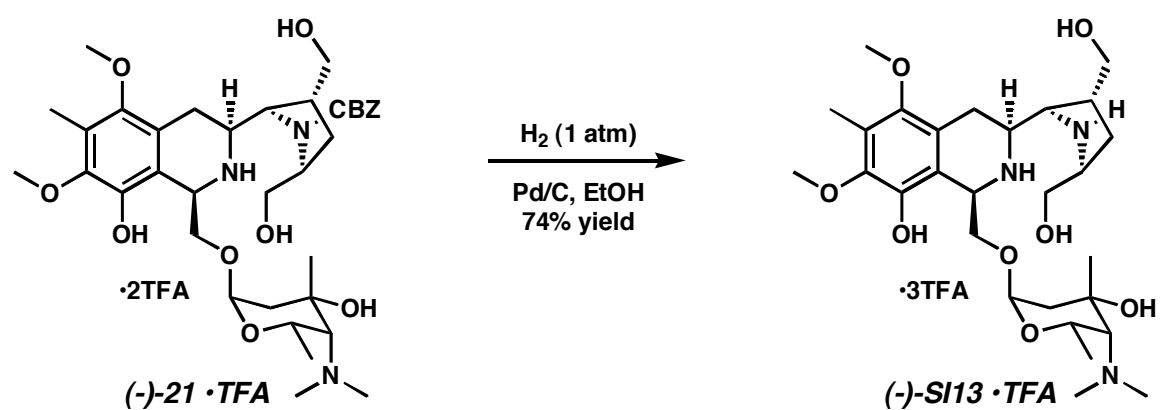

Tetrahydroisoquinoline (-)-SI13. To a solution of (-)-21 bis-trifluoroacetate (74 $\mathrm{mg}, 80.7$ $\square \mathrm{mol})$ in ethanol $(8 \mathrm{~mL})$ was added palladium on carbon $(10 \% \mathrm{w} / \mathrm{w}, 15 \mathrm{mg})$. The reaction was purged and flushed with hydrogen, then maintained under a balloon of hydrogen for $30 \mathrm{~min}$. The mixture was filtered through celite, concentrated, and purified by preparative HPLC to provide ()-SI13 tris-trifluoroacetate (53.5 mg, 74\% yield) as a colorless, highly viscous oil: $\mathrm{R}_{\mathrm{F}} 0.25$ (10:90 methanol: chloroform, eluted twice); ${ }^{1} \mathrm{H}$ NMR $\left(300 \mathrm{MHz}, \mathrm{D}_{2} \mathrm{O}\right) \square 5.17(\mathrm{~s}, 1 \mathrm{H}), 5.11(\mathrm{~d}, J=3.9$ $\mathrm{Hz}, 1 \mathrm{H}), 4.66$ (dd, $J=10.8,3.3 \mathrm{~Hz}, 1 \mathrm{H}), 4.01-3.85$ (comp m, 4H), 3.82-3.61 (comp m, 5H), $3.77(\mathrm{~s}, 3 \mathrm{H}), 3.71(\mathrm{~s}, 3 \mathrm{H}), 3.34(\mathrm{dd}, J=16.8,2.4 \mathrm{~Hz}, 1 \mathrm{H}), 3.04(\mathrm{~s}, 6 \mathrm{H}), 3.00(\mathrm{~s}, 1 \mathrm{H}), 2.89$ (dd, $J$ $=16.5,12.6 \mathrm{~Hz}, 1 \mathrm{H}), 2.75(\mathrm{~m}, 1 \mathrm{H}), 2.24(\mathrm{~s}, 3 \mathrm{H}), 2.22-1.93($ comp m, 3H), $1.89(\mathrm{~d}, J=15.0 \mathrm{~Hz}$, 
$1 \mathrm{H}), 1.52(\mathrm{~d}, J=7.2 \mathrm{~Hz}, 3 \mathrm{H}), 0.95(\mathrm{~s}, 3 \mathrm{H}) ;{ }^{13} \mathrm{C}$ NMR $\left(125 \mathrm{MHz}, \mathrm{D}_{2} \mathrm{O}\right) \square$ 148.2, 145.0, 142.9, $125.6,122.3,114.1,96.2,70.2,67.2,64.2,64.0,62.5,62.1,61.1,61.0,60.9,60.1,55.6,54.2$, 47.2, 43.5, 41.9, 37.3, 28.5, 27.9, 24.8, 17.5, 9.1; IR (NaCl/film) 3296, 2947, 1682, 1468, 1417 , 1204, 1131, 1054, 1004, 800, $723 \mathrm{~cm}^{-1}$; HRMS (FAB) calc'd for $\left[\mathrm{C}_{28} \mathrm{H}_{47} \mathrm{~N}_{3} \mathrm{O}_{8}+\mathrm{H}\right]^{+}: \mathrm{m} / z$ 554.3441 , found $554.3463 ;[\square]_{\mathrm{D}}{ }^{24}-83.1^{\circ}(\mathrm{c}=0.25$, methanol $)$.
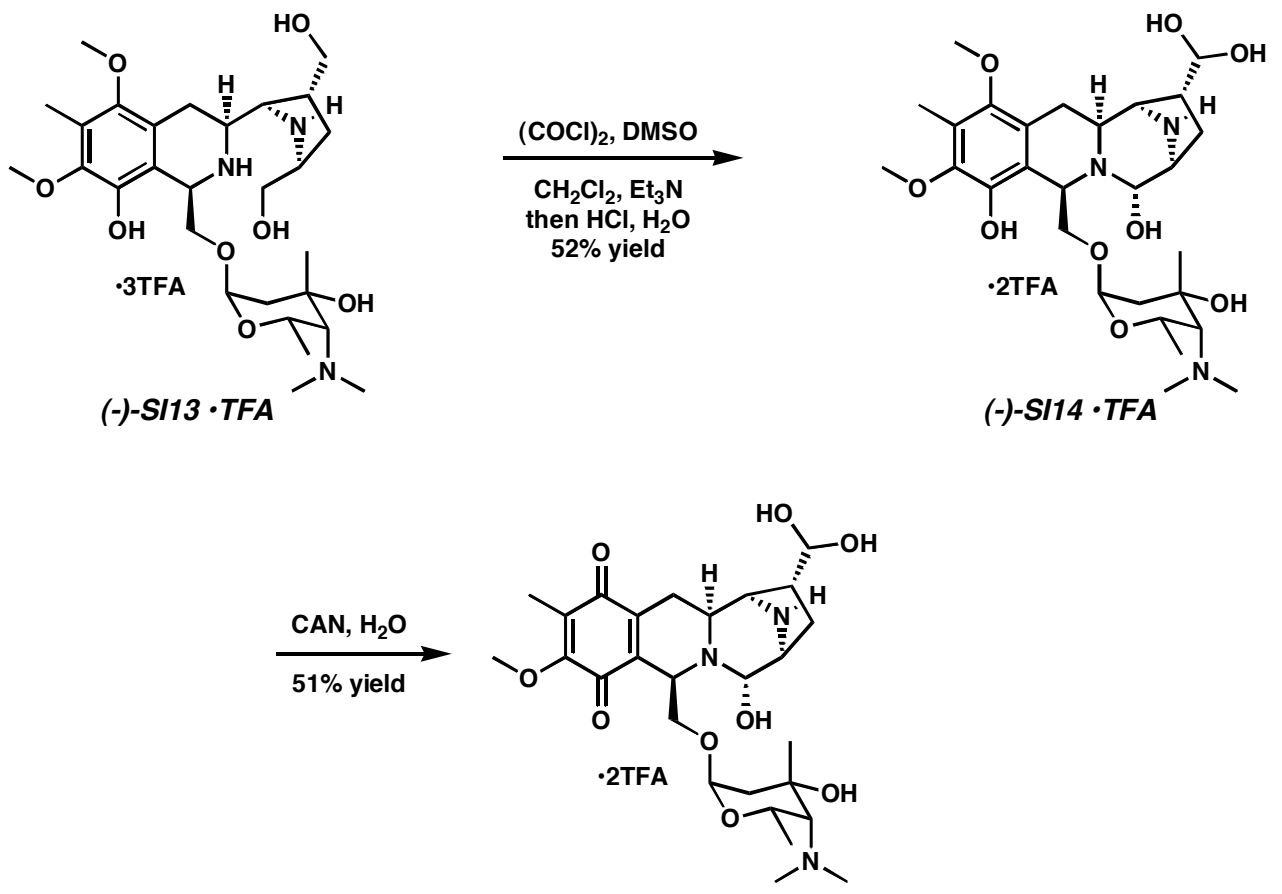

$(-)-1$

SI14 and Lemonomycin (-)-1. To a $-78{ }^{\circ} \mathrm{C}$ solution of dimethyl sulfoxide (7.9 $\left.\square \mathrm{L}, 111.6 \square \mathrm{mol}\right)$ in dichloromethane $(744 \square \mathrm{L})$ was added oxalyl chloride $(4.9 \square \mathrm{L}, 55.8 \square \mathrm{mol})$. After $30 \mathrm{~min}$, this solution was added via cannula to a $-78{ }^{\circ} \mathrm{C}$ solution of (-)-SI13 (10.0 mg, $\left.11.16 \square \mathrm{mol}\right)$ in 4:1 dichloromethane:dimethyl sulfoxide $(560 \square \mathrm{L})$. The reaction was maintained at $-78{ }^{\circ} \mathrm{C}$ for $1 \mathrm{~h}$, after which triethylamine $(23.3 \square \mathrm{L}, 167.4 \square \mathrm{mol})$ was added. After an additional $15 \mathrm{~min}$, the reaction was warmed to $0{ }^{\circ} \mathrm{C}$ over $10 \mathrm{~min}$. The reaction was extracted into $1 \mathrm{M}$ aqueous hydrochloric acid $(2 \times 1 \mathrm{ml})$ and warmed to $20^{\circ} \mathrm{C}$ for $41 \mathrm{~h}$. The mixture was then purified by preparative HPLC to provide SI14 bis-trifluoroacetate $(4.6 \mathrm{mg}, 52 \%$ yield) as a colorless film, which was used immediately in the next reaction.

To a cooled $\left(0^{\circ} \mathrm{C}\right)$ solution of SI14 $(4.6 \mathrm{mg}, 5.78 \square \mathrm{mol})$ in water $(1.16 \mathrm{~mL})$ was added cerium(IV) ammonium nitrate $(7.9 \mathrm{mg}, 14.5 \square \mathrm{mol})$. After $10 \mathrm{~min}$, the reaction mixture was purified by preparative HPLC to provide lemonomycin ((-)-1, $2.3 \mathrm{mg}, 51 \%$ yield) as a yellow film: ${ }^{1} \mathrm{H}$ NMR $\left(600 \mathrm{MHz}, \mathrm{D}_{2} \mathrm{O}\right) \square 5.16(\mathrm{~d}, J=4.8 \mathrm{~Hz}, 1 \mathrm{H}), 5.08(\mathrm{~d}, J=4.8 \mathrm{~Hz}, 1 \mathrm{H}), 4.90(\mathrm{~d}, J$ $=3.6 \mathrm{~Hz}, 1 \mathrm{H}), 4.29(\mathrm{~s}, 1 \mathrm{H}), 4.08(\mathrm{dd}, J=6.6,2.4 \mathrm{~Hz}, 1 \mathrm{H}), 4.01(\mathrm{~s}, 1 \mathrm{H}), 3.98$ (br q, $J=7.2 \mathrm{~Hz}$, $1 \mathrm{H}), 3.91(\mathrm{~s}, 3 \mathrm{H}), 3.77(\mathrm{dd}, J=10.8,2.4 \mathrm{~Hz}, 1 \mathrm{H}), 3.66(\mathrm{dd}, J=10.2,1.5 \mathrm{~Hz}, 1 \mathrm{H}), 3.37(\mathrm{br} \mathrm{d}, J$ $=9.6 \mathrm{~Hz}, 1 \mathrm{H}), 3.16(\mathrm{~s}, 1 \mathrm{H}), 3.054(\mathrm{~s}, 3 \mathrm{H}), 3.048(\mathrm{~s}, 3 \mathrm{H}), 2.77(\mathrm{dd}, J=17.4,2.4 \mathrm{~Hz}, 1 \mathrm{H}), 2.64$ (ddd, $J=9.6,4.8,4.8 \mathrm{~Hz}, 1 \mathrm{H}), 2.17-1.98$ (comp m, 4H), 1.97 (s, 3H), $1.92(\mathrm{~d}, J=14.4 \mathrm{~Hz}, 1 \mathrm{H})$, $1.47(\mathrm{~d}, J=7.2 \mathrm{~Hz}, 3 \mathrm{H}), 1.32$ (s, 3H); ${ }^{13} \mathrm{C}$ NMR (125 MHz, $\left.\mathrm{D}_{2} \mathrm{O}\right) \square$ 190.3, 184.6, 158.2, 144.6, 140.6, 133.4, 99.8, 92.9, 81.3, 72.6, 71.3, 69.7, 64.9, 64.1, 63.3, 62.8, 54.4, 52.4, 49.7, 44.4, 43.4, 
40.6, 31.3, 28.5, 26.5, 19.9, 11.0; IR (NaCl/film) 3249, 3094, 2943, 1673, 1611, 1443, 1387, $1329,1207,1137,802,724 \mathrm{~cm}^{-1}$; UV-Vis (methanol) $\square_{\max } 272,363 \mathrm{~nm}$; HRMS (FAB) calc'd for $\left[\mathrm{C}_{27} \mathrm{H}_{41} \mathrm{~N}_{3} \mathrm{O}_{9}-\mathrm{OH}\right]^{+}: m / z 534.2815$, found 534.2839; [प] $]_{\mathrm{D}}^{23}-124.2^{\circ}\left(\mathrm{c}=0.1, \mathrm{H}_{2} \mathrm{O}\right)$. 


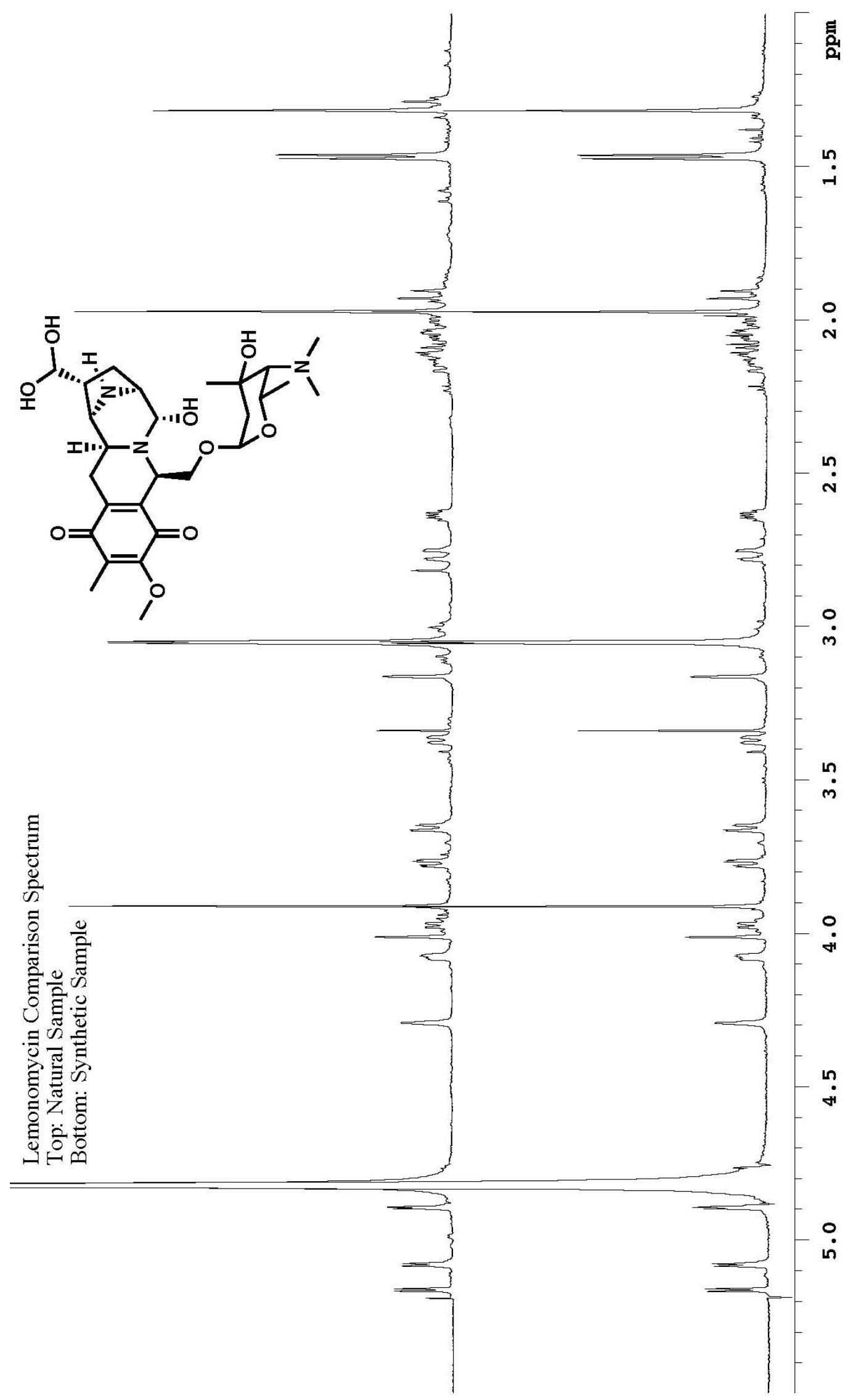


FT-IR of Lemonomycin, Synthetic sample

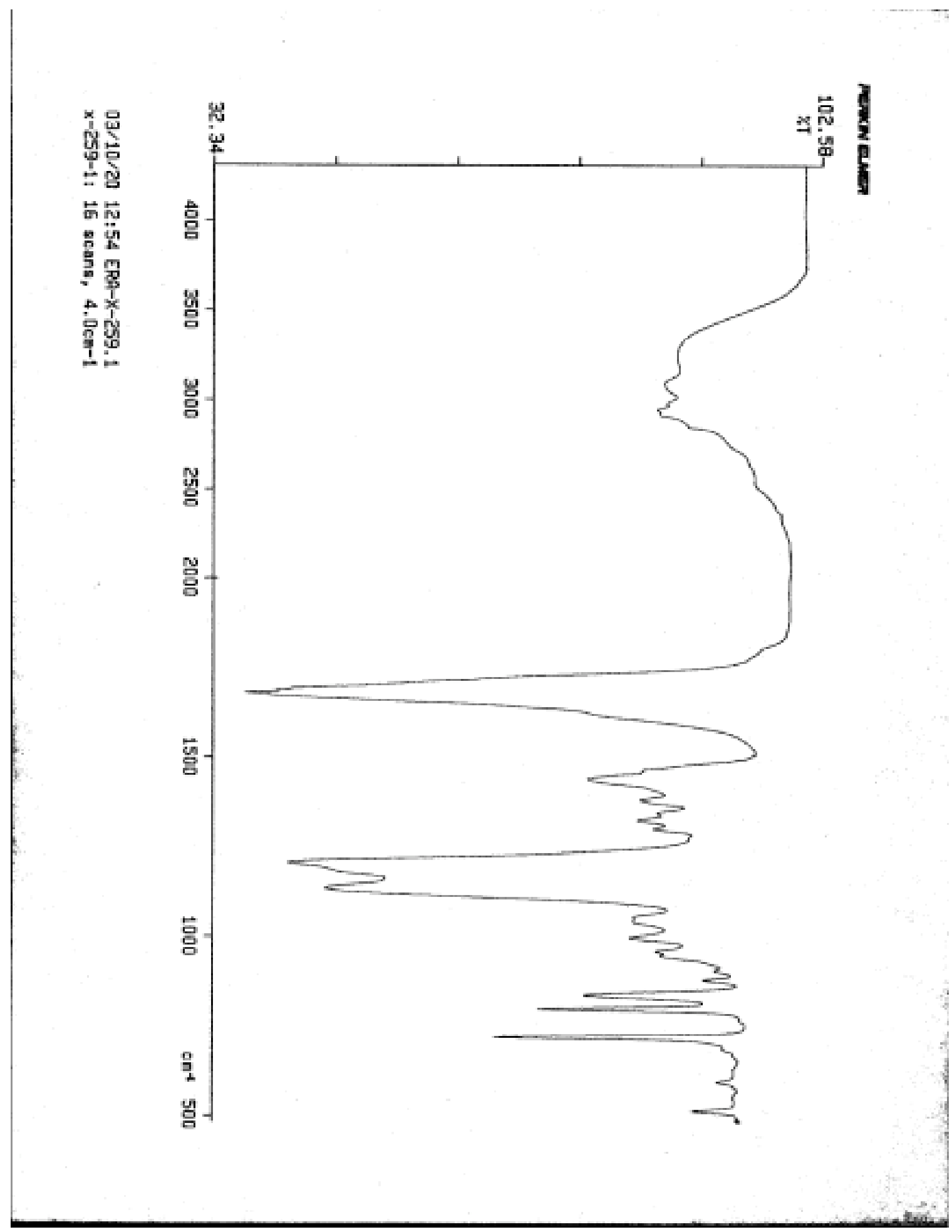


FT-IR of Lemonomycin, Natural sample

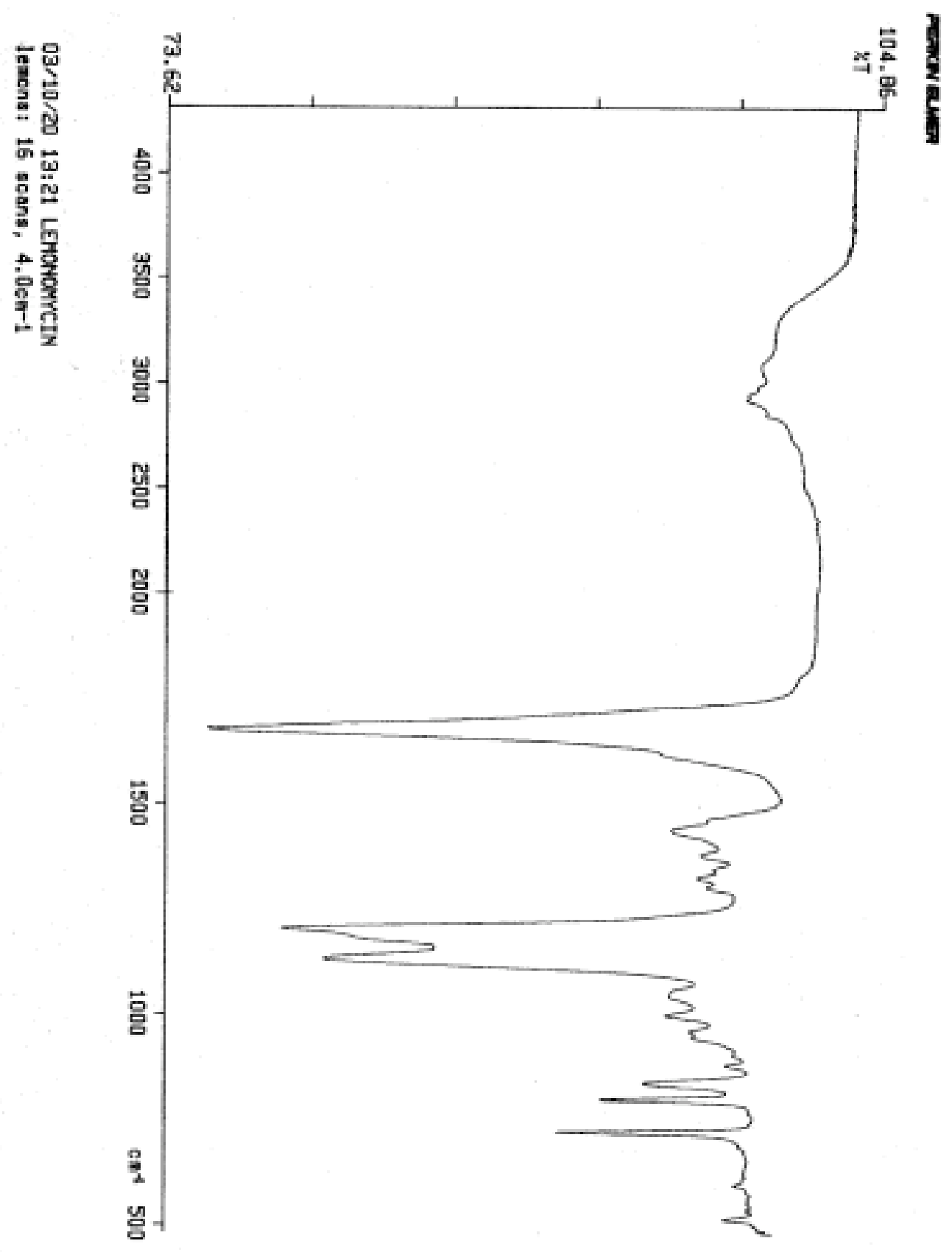



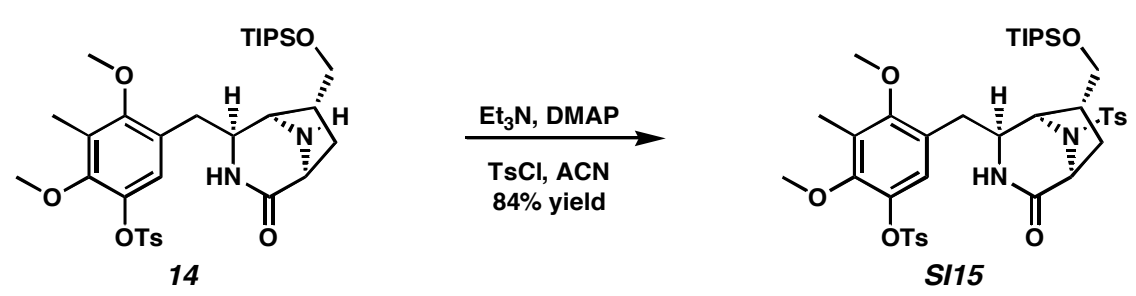

Tosamide SI15. To a solution of $14(200 \mathrm{mg}, 310 \square \mathrm{mol})$ in acetonitrile $(6.2 \mathrm{~mL})$ were added

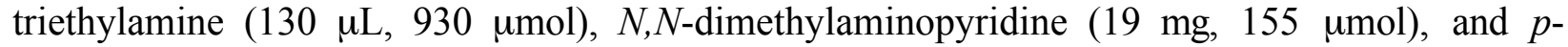
toluenesulfonyl chloride $(88.7 \mathrm{mg}, 465 \square \mathrm{mol})$. The reaction was maintained at $20^{\circ} \mathrm{C}$ for $1.5 \mathrm{~h}$, diluted with ethyl acetate $(100 \mathrm{~mL})$, washed with saturated aqueous ammonium chloride $(50 \mathrm{~mL})$ and saturated aqueous sodium chloride $(50 \mathrm{~mL})$, dried over sodium sulfate, concentrated, and purified by flash chromatography on silica gel (40:60 to 50:50 ethyl acetate:hexanes) to provide SI15 (208 mg, 84\% yield) as a colorless oil: $\mathrm{R}_{\mathrm{F}} 0.30$ (50:50 ethyl acetate:hexanes); ${ }^{1} \mathrm{H}$ NMR (300 $\left.\mathrm{MHz}, \mathrm{CDCl}_{3}\right) \square 7.82(\mathrm{~d}, J=8.4 \mathrm{~Hz}, 2 \mathrm{H}), 7.77(\mathrm{~d}, J=8.1 \mathrm{~Hz}, 2 \mathrm{H}), 7.37(\mathrm{~d}, J=7.8 \mathrm{~Hz}, 2 \mathrm{H})$, $7.29(\mathrm{~d}, J=8.1 \mathrm{~Hz}, 2 \mathrm{H}), 6.72(\mathrm{~s}, 1 \mathrm{H}), 5.19(\mathrm{~s}, 1 \mathrm{H}), 4.35(\mathrm{~s}, 1 \mathrm{H}), 4.18(\mathrm{~d}, J=6.6 \mathrm{~Hz}, 1 \mathrm{H}), 3.89$ $(\mathrm{m}, 1 \mathrm{H}), 3.70(\mathrm{~s}, 3 \mathrm{H}), 3.67(\mathrm{~s}, 3 \mathrm{H}), 3.61(\mathrm{dd}, J=9.8,5.6 \mathrm{~Hz}, 1 \mathrm{H}), 3.49($ app t, $J=9.9 \mathrm{~Hz}, 1 \mathrm{H})$, 2.72-2.53 (comp m, 3H), 2.48 (s, 3H), 2.40 (s, 3H), 2.17 (dd, $J=12.9,8.7 \mathrm{~Hz}, 1 \mathrm{H}), 2.16(\mathrm{~s}, 3 \mathrm{H})$, 1.67 (ddd, $J=12.9,6.6,6.3 \mathrm{~Hz}, 1 \mathrm{H}), 1.10$ (br s, 21H); ${ }^{13} \mathrm{C}$ NMR $\left(75 \mathrm{MHz}, \mathrm{CDCl}_{3}\right) \square 170.0$, $156.3,155.7,151.3,145.7,144.4,139.1,137.1,133.3,130.1,130.0,128.6,127.6,125.0,122.1$, $65.0,61.1,61.0,60.8,60.4,56.9,39.8,34.3,32.3,22.0,21.8,18.3,12.1,10.3 ; \mathrm{IR}(\mathrm{NaCl} / \mathrm{film})$ 3334, 3200, 2943, 2866, 1687, 1483, 1376, 1176, 1182, 1107, 1007, 995, 664, $551 \mathrm{~cm}^{-1}$; HRMS (FAB) calc'd for $\left[\mathrm{C}_{40} \mathrm{H}_{56} \mathrm{~N}_{2} \mathrm{O}_{9} \mathrm{~S}_{2} \mathrm{Si}+\mathrm{H}\right]^{+}: \mathrm{m} / z$ 801.3275, found 801.3296.
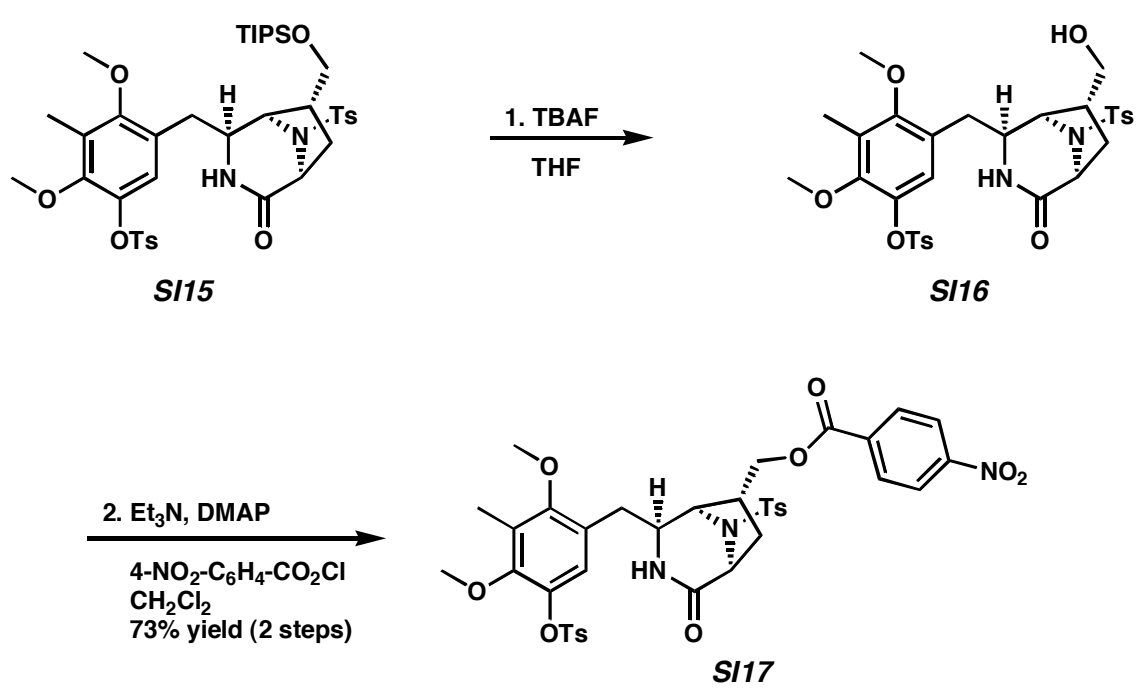

Nitrobenzoate SI17. To a solution of SI15 (175 mg, $219 \square \mathrm{mol})$ in tetrahydrofuran (4.4 mL) was added tetrabutylammonium fluoride $(1 \mathrm{M}$ in tetrahydrofuran, $328 \square \mathrm{L}, 328 \square \mathrm{mol})$. After 10 min, the reaction was diluted with ethyl acetate $(50 \mathrm{~mL})$, washed with water $(50 \mathrm{~mL})$ followed by saturated aqueous sodium chloride $(35 \mathrm{~mL})$, dried over sodium sulfate, concentrated, and filtered through a pad of silica gel (ethyl acetate eluent) to provide SI16 (140 mg, 99\% yield), which was used without further purification. 
To a solution of SI16 $(60 \mathrm{mg}, 93 \square \mathrm{mol})$ in dichloromethane $(1.9 \mathrm{~mL})$ were added $\mathrm{N}, \mathrm{N}$ dimethylaminopyridine $(5.7 \mathrm{mg}, 46.5 \square \mathrm{mol})$, triethylamine $(25.9 \square \mathrm{L}, 186 \square \mathrm{mol})$, and 4nitrobenzoyl chloride $(25.9 \mathrm{mg}, 139.5 \square \mathrm{mol})$. After $10 \mathrm{~min}$ the reaction was diluted with dichloromethane $(35 \mathrm{~mL})$, washed with water $(35 \mathrm{~mL})$, dried over sodium sulfate, concentrated, and purified by flash chromatography on silica gel (60:40 ethyl acetate:hexanes eluent) to provide SI17 (54.5 mg, 74\% yield) as a white, crystalline solid. Crystals of sufficient quality for X-ray analysis were grown from acetone:water by slow evaporation: m.p. $156.5-158{ }^{\circ} \mathrm{C}$ (corrected for benzanilide, mp. $\left.163-163.5^{\circ} \mathrm{C}^{5}\right) ; \mathrm{R}_{\mathrm{F}} 0.47$ (85:15 ethyl acetate:hexanes); ${ }^{1} \mathrm{H}$ NMR $(300 \mathrm{MHz}$, $\left.\mathrm{CDCl}_{3}\right) \square 8.31(\mathrm{~d}, J=8.7 \mathrm{~Hz}, 2 \mathrm{H}), 8.21(\mathrm{~d}, J=8.7 \mathrm{~Hz}, 2 \mathrm{H}), 7.82(\mathrm{~d}, J=8.4 \mathrm{~Hz}, 2 \mathrm{H}), 7.79(\mathrm{~d}, J$ $=9.3 \mathrm{~Hz}, 2 \mathrm{H}), 7.36(\mathrm{~d}, J=9.0 \mathrm{~Hz}, 2 \mathrm{H}), 7.33(\mathrm{~d}, J=8.1 \mathrm{~Hz}, 2 \mathrm{H}), 6.85(\mathrm{~s}, 1 \mathrm{H}), 5.22(\mathrm{~s}, 1 \mathrm{H})$, 4.43 (dd, $J=11.1,6.6 \mathrm{~Hz}, 1 \mathrm{H}), 4.38-4.28$ (comp m, 2H), 4.26 (d, $J=6.6 \mathrm{~Hz}, 1 \mathrm{H}), 3.93$ (ddd, $J$ $=8.4,4.4,4.1 \mathrm{~Hz}, 1 \mathrm{H}), 3.67(\mathrm{~s}, 3 \mathrm{H}), 3.65(\mathrm{~s}, 3 \mathrm{H}), 3.00(\mathrm{ddd}, J=14.3,7.7,6.9 \mathrm{~Hz}, 1 \mathrm{H}), 2.69$ (dd, $J=13.7,5.0 \mathrm{~Hz}, 1 \mathrm{H}), 2.59$ (dd, $J=13.8,8.7 \mathrm{~Hz}, 1 \mathrm{H}$ ), 2.46 (s, 3H), 2.42 (s, 3H), 2.37 (dd, $J$ $=13.2,9.0 \mathrm{~Hz}, 1 \mathrm{H}), 2.11(\mathrm{~s}, 3 \mathrm{H}), 2.02(\mathrm{ddd}, J=13.2,6.6,6.6 \mathrm{~Hz}, 1 \mathrm{H}) ;{ }^{13} \mathrm{C}$ NMR $(75 \mathrm{MHz}$, $\left.\mathrm{CDCl}_{3}\right) \square 169.6,164.6,156.1,151.3,151.0,145.8,144.8,139.1,136.6,135.2,133.2,131.0$, $130.3,130.0,128.6,127.6,127.5,124.1,124.0,122.2,67.1,61.0,60.94,60.91,60.4,56.7,36.0$, 35.2, 32.2, 22.0, 21.8, 10.3; IR (NaCl/film) 3338, 3207, 2944, 1726, 1688, 1528, 1349, 1275, $1176,1161,1105,1003,721 \mathrm{~cm}^{-1}$; HRMS (FAB) calc'd for $\left[\mathrm{C}_{38} \mathrm{H}_{39} \mathrm{~N}_{3} \mathrm{O}_{12} \mathrm{~S}_{2}+\mathrm{H}\right]^{+}: \mathrm{m} / z$ 794.2054, found 794.2047. 


\section{Crystal structure of SI17.}

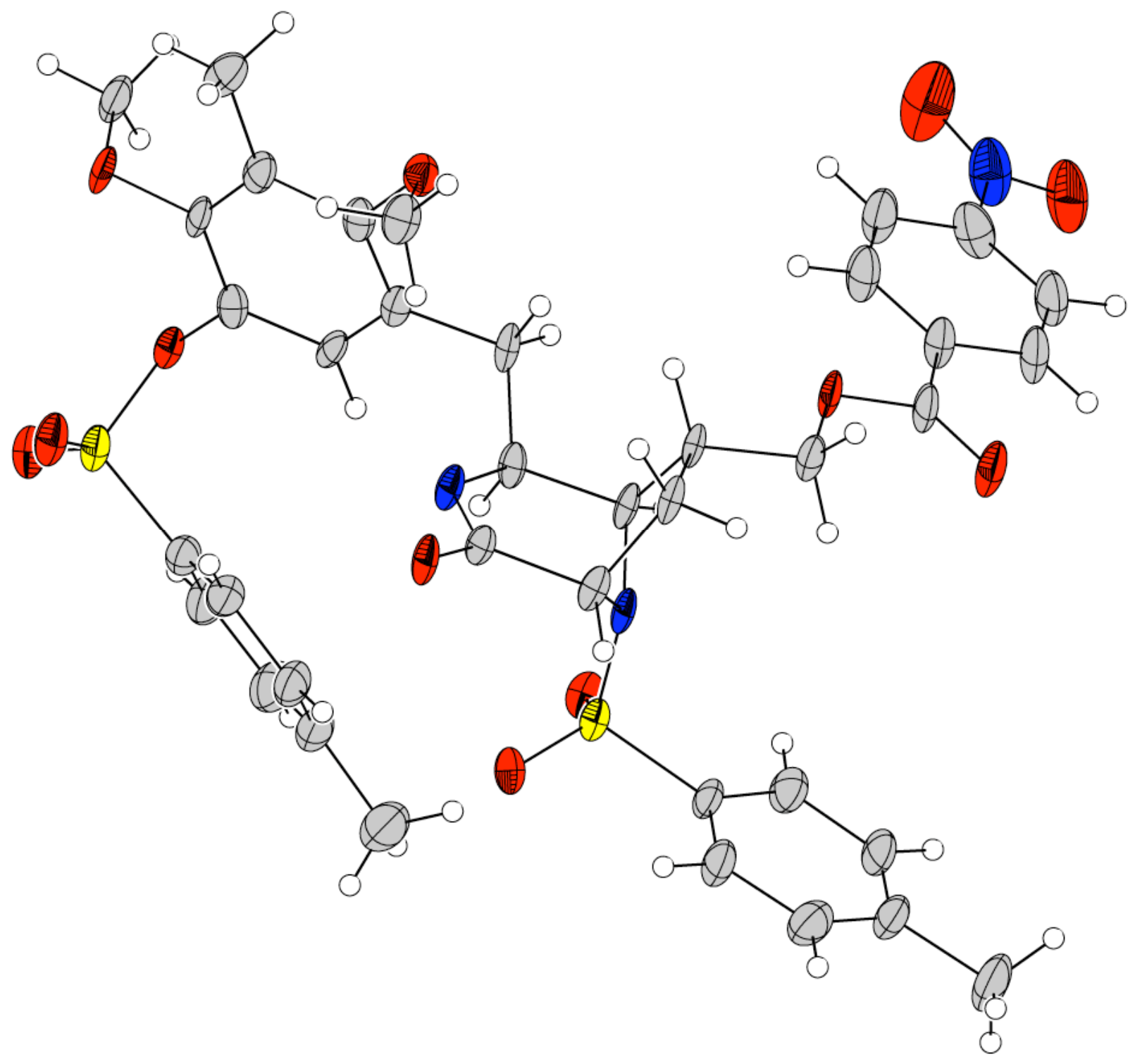


Table 2. Crystal data and structure refinement for SI17 (CCDC 219709).

Empirical formula

Formula weight

Crystallization Solvent

Crystal Habit

Crystal size

Crystal color
$\mathrm{C}_{38} \mathrm{H}_{38} \mathrm{~N}_{3} \mathrm{O}_{12} \mathrm{~S}_{2} \cdot \mathrm{C}_{3} \mathrm{H}_{6} \mathrm{O}$

850.91

Acetone

Blade

$0.59 \times 0.21 \times 0.07 \mathrm{~mm}^{3}$

Colorless

\section{Data Collection}

Preliminary Photos

Rotation

Type of diffractometer

Bruker SMART 1000

Wavelength

$0.71073 \AA \mathrm{MoKa}$

Data Collection Temperature

100(2) K

q range for 4790 reflections used in lattice determination

2.31 to $27.48^{\circ}$

Unit cell dimensions

Volume

$\mathrm{a}=11.907(2) \AA$

$\mathrm{a}=66.875(2)^{\circ}$

$\mathrm{b}=13.420(2) \AA$

$\mathrm{b}=69.845(3)^{\circ}$

$\mathrm{c}=14.819(3) \AA$

$\mathrm{g}=75.856(3)^{\circ}$

2028.1(6) $\AA^{3}$

Z

Crystal system

2

Triclinic

Space group

P-1

Density (calculated)

$1.393 \mathrm{Mg} / \mathrm{m}^{3}$

$\mathrm{F}(000)$

894

Data collection program

Bruker SMART v5.054

q range for data collection

1.56 to $28.18^{\circ}$

Completeness to $\mathrm{q}=28.18^{\circ}$

$88.5 \%$

Index ranges

$-15 \leq \mathrm{h} \leq 15,-17 \leq \mathrm{k} \leq 17,-19 \leq 1 \leq 18$

Data collection scan type

$\square$ scans at $3 \square$ settings

Data reduction program

Bruker SAINT v6.022

17713

$8831\left[\mathrm{R}_{\mathrm{int}}=0.1081\right]$

$0.202 \mathrm{~mm}^{-1}$

None

Absorption correction

0.9860 and 0.8903 


\section{Table 1 (cont.)}

\section{Structure solution and Refinement}

Structure solution program

Primary solution method

Secondary solution method

Hydrogen placement

Structure refinement program

Refinement method

Data / restraints / parameters

Treatment of hydrogen atoms

Goodness-of-fit on $\mathrm{F}^{2}$

Final $\mathrm{R}$ indices [I $>2 \mathrm{~s}(\mathrm{I}), 4683$ reflections]

$\mathrm{R}$ indices (all data)

Type of weighting scheme used

Weighting scheme used

Max shift/error

Average shift/error

Largest diff. peak and hole
SHELXS-97 (Sheldrick, 1990)

Direct methods

Difference Fourier map

Geometric positions

SHELXL-97 (Sheldrick, 1997)

Full matrix least-squares on $\mathrm{F}^{2}$

$8831 / 5 / 517$

Riding

1.605

$\mathrm{R} 1=0.0784, w \mathrm{R} 2=0.1558$

$\mathrm{R} 1=0.1543, w \mathrm{R} 2=0.1704$

Sigma

$w=1 / \square 2(\mathrm{Fo} 2)$

0.001

0.000

1.430 and -0.784 e. $\AA^{-3}$

\section{Special Refinement Details}

Refinement of F2 against ALL reflections. The weighted R-factor $(w \mathrm{R})$ and goodness of fit $(\mathrm{S})$ are based on F2, conventional R-factors $(\mathrm{R})$ are based on $\mathrm{F}$, with $\mathrm{F}$ set to zero for negative $\mathrm{F} 2$. The threshold expression of $\mathrm{F} 2>2 \square(\mathrm{F} 2)$ is used only for calculating R-factors(gt) etc. and is not relevant to the choice of reflections for refinement. R-factors based on F2 are statistically about twice as large as those based on F, and R-factors based on ALL data will be even larger.

All esds (except the esd in the dihedral angle between two 1.s. planes) are estimated using the full covariance matrix. The cell esds are taken into account individually in the estimation of esds in distances, angles and torsion angles; correlations between esds in cell parameters are only used when they are defined by crystal symmetry. An approximate (isotropic) treatment of cell esds is used for estimating esds involving 1.s. planes. 


\section{References.}

1) Szechner, B; Achmatowicz, O.; Galdecki, Z.; Fruzinski, A. Tetrahedron 1994, 50, 7611-7624.

2) (a) Godfrey, I. M.; Sargent, M. V.; Elix, J. A. J. Chem. Soc., Perkin Trans. 1 1974, 1353-1354. (b) Luly, J. R.; Rapoport, H. J. Org. Chem. 1981, 46, 2745-2752.

3) Yates, N. D.; Peters, D. A.; Allway, P. A.; Beddoes, R. L.; Scopes, D. I. C.; Joule, J. A. Heterocycles 1995, 40, 331-347.

4) Thom, C.; Kocienski, P. Synthesis 1992, 582-586.

5) Azumaya, I.; Kagechika, H.; Fujiwara, Y.; Itoh, M.; Yamaguchi, K.; Shudo, K. J. Am. Chem. Soc. 1991, 113, 2833-2838. 